\title{
Previsões multiescala de vazões para o sistema hidrelétrico brasileiro utilizando ponderação bayesiana de modelos (BMA)
}

\author{
Multiscale streamflow forecasts for the Brazilian hydropower system using bayesian \\ model averaging (BMA)
}

\author{
Vinicius Grossi de Oliveira ${ }^{1}$ e Carlos Henrique Ribeiro Lima ${ }^{2}$ \\ ${ }^{1}$ Agência Nacional de Energia Elétrica, Brasília, DF, Brasil \\ ${ }^{2}$ Universidade de Brasília, Brasília, DF, Brasil \\ E-mails: vinicius.grossi@yahoo.com.br (VGO), chrlima@unb.br (CHRL)
}

Recebido: Março 07, 2016 - Revisado: Maio 07, 2016 - Aceito: Maio 12, 2016

\begin{abstract}
RESUMO
O uso de sistemas eficientes de previsão de afluências nas diversas escalas temporais permite otimizar a operação do conjunto de reservatórios hidrelétricos brasileiros, elevando o grau de segurança no fornecimento de energia elétrica e minimizando os custos operacionais. Entretanto, os modelos atuais de previsão utilizados pelo Operador Nacional do Sistema Elétrico (ONS) tendem a ser limitados no horizonte de previsão e na modelagem da dependência existente entre as diversas escalas de tempo, reduzindo a qualidade das previsões. Neste trabalho é proposta uma nova contribuição para os modelos de previsão de afluências em uso pelo ONS a partir do conceito de ponderação bayesiana de modelos (BMA), que permite integrar previsões mensais e semanais de vazões com objetivo de melhorar o desempenho das previsões semanais. As previsões mensais são obtidas por meio de um modelo periódico auto-regressivo exógeno (PARX), que busca captar a persistência das vazões na parte auto-regressiva e a contribuição do escoamento superficial na parcela exógena por meio do uso de informações climáticas de larga escala. Previsões semanais de afluência com até seis semanas de antecedência são obtidas a partir das informações disponibilizadas pelo ONS nos relatórios do Programa Mensal de Operação (PMO). A metodologia proposta é aplicada em séries de afluências semanais aos 28 principais reservatórios hidroelétricos brasileiros. Os resultados de previsão semanal de afluências obtidos com a ponderação das saídas dos modelos de previsão semanal e mensal indicam uma melhoria significativa em indicadores de desempenho de previsões (NS, MAPE e DM) quando comparados com os resultados de previsão oriundos do modelo semanal isolado. Os ganhos obtidos nos indicadores de desempenho são mais significativos a partir da segunda semana de antecedência. A abordagem proposta é flexível em termos de implementação, permitindo integrar outras escalas de previsão assim como diferentes modelos preditivos (por exemplo, modelos de base física).
\end{abstract}

Palavras-chave: Ponderação bayesiana de modelos; BMA; Previsões de vazão; Reservatórios; Hidroelétricas.

\begin{abstract}
The use of efficient streamflow forecast systems at different time scales allows the operational optimization of the Brazilian interconnected hydropower reservoirs, raising the security level of electricity supply and minimizing operating costs. However, current forecasting models used by the National Electric System Operator (ONS) tend to be limited over the forecast horizon and in the modeling of the dependence structure across the various time scales, thus reducing the quality of forecasts. This paper proposes a new contribution to the streamflow forecast models by exploring the concept of Bayesian Model Averaging (BMA), which allows integrating weekly and monthly forecasts in order to improve the skill of weekly predictions. The monthly forecasts are obtained from a periodic auto-regressive exogenous model (PARX), which attempts to capture the persistence of flow in the auto-regressive part and the runoff contribution in the exogenous portion through the use of climate information. Weekly streamflow forecasts with up to six weeks lead time are obtained from information made available by ONS in the Monthly Operational Program (PMO) reports. The proposed methodology is tested using weekly inflow series from the 28 major Brazilian hydropower reservoirs. The weekly streamflow forecasts results obtained from the weighting of the outputs from the weekly and monthly models indicate a significant improvement in skill based on common performance indicators (NS, MAPE and DM) when compared with forecasts derived from
\end{abstract}


Oliveira e Lima

the isolated weekly model. The gains in performance indicators are more significant for lead times beyond two weeks. The proposed approach is flexible in terms of implementation, allowing the incorporation of the other forecast scales as well as different forecast models (e.g. physical models).

Keywords: Bayesian model averaging; BMA; Streamflow forecasts; Reservoirs; Hydroelectric power plants.

\section{INTRODUÇÃO}

As usinas hidroelétricas têm papel fundamental na produção de energia elétrica no Brasil, contribuindo com aproximadamente 64,7\% (92,5 GW) da capacidade instalada total do país (ANEEL, 2016) e respondendo por quase toda a produção de energia elétrica nacional durante períodos favoráveis de precipitação e acumulação nos reservatórios do sistema. Milhares de quilômetros de linhas de transmissão interligam as principais usinas em quatro subsistemas de produção (Norte, Nordeste, Sul e Sudeste). A energia gerada em cada um dos subsistemas é utilizada preferencialmente para o abastecimento da demanda delimitada pela região do subsistema, mas a interligação do sistema permite o intercâmbio de energia entre os subsistemas a fim de maximizar a eficiência global e, juntamente com as demais fontes, suprir a demanda de energia elétrica do país. A hidroenergia disponível para um determinado período futuro, entretanto, é incerta e depende fortemente do armazenamento atual dos reservatórios e das vazões afluentes futuras aos mesmos, dentre outras variáveis.

Com objetivo de minimizar o custo esperado de produção hidroenergética para certo horizonte temporal, de suprir a demanda e minimizar perdas via vertimentos, o ONS busca estimar a disponibilidade hídrica em cada reservatório a partir de previsões de afluências em diversas escalas temporais, que servirão de base para a definição das regras operacionais ótimas de cada reservatório (ver, por exemplo, COSTA et al., 2007; GOMIDE, 2004; MACEIRA; PENNA; DAMÁZIO, 2006; BARROS et al., 2003). Sabe-se que o uso ineficaz da água na operação do sistema de reservatórios implicará em custos adicionais de geração térmica complementar e em desperdícios de água por vertimentos desnecessários, pela alta evaporação dos reservatórios e pela operação das centrais hidrelétricas fora das faixas de maior eficiência.

Os modelos de previsão adotados pelo ONS operam basicamente em três escalas: diárias, semanais e mensais. A maioria dos modelos atuais de previsão pertence à classe geral de modelos auto-regressivos (AR, ARMA, PAR, PARMA, etc), construídos e operados independentemente para cada reservatório. A construção desses modelos adota como premissa básica a independência mútua das séries de afluência, uma vez conhecidas as covariáveis utilizadas nos modelos. Embora essa suposição possa garantir que em previsões de curto prazo (menores do que cinco dias) seja mantida a variabilidade espacial observada nos dados históricos, a persistência da série de vazões e o uso de informações passadas tende a explicar pouco a variância de vazões de longo prazo, o que pode acarretar na violação dessa premissa (LIMA, 2014). Em geral, esses modelos têm o seu desempenho reduzido quando a antecedência (lead time) das previsões é superior a duas semanas, como pode ser observado nos relatórios do ONS que avaliam anualmente o desempenho das previsões de vazões (ONS, 2015). Além disso, as previsões feitas em escalas semanais são independentes daquelas feitas em escala mensal, ou seja, nenhuma informação quantitativa das previsões mensais é utilizada no modelo semanal e nas suas previsões, embora as políticas operacionais multiescala (por exemplo, regras de operação do dia seguinte e curvas de aversão ao risco) estejam conectadas temporalmente.

Assim, busca-se neste trabalho aperfeiçoar as previsões de vazões ao sistema hidroelétrico brasileiro nas escalas diária e semanal a partir da integração das previsões semanais de afluências realizadas pelo ONS com um modelo estatístico de previsões mensais de vazão que considera informação climática de larga escala. A conexão multiescala dos modelos de previsão de vazões é realizada com base no conceito de ponderação bayesiana de modelos (Bayesian Model Averaging, BMA), que permite atualizar as previsões semanais de vazões a partir da média ponderada das previsões mensais e semanais. Os pesos e respectivas incertezas atribuídos a cada modelo são estimados num contexto bayesiano a partir do desempenho individual observado em um determinado conjunto de dados históricos.

Após essa introdução, este artigo é organizado em outras três seções. Na seção a seguir é apresentada a metodologia do trabalho, onde são descritos a região de estudo e dados hidroclimáticos e é apresentada a formulação matemática básica dos modelos de previsão utilizados. Na terceira seção são apresentados e discutidos, para diversos reservatórios do sistema, os resultados do modelo BMA em termos de indicadores de desempenho e estimativas dos pesos. As considerações finais deste trabalho são realizadas na última seção.

\section{METODOLOGIA}

\section{Abrangência dos dados e região de estudo}

A eficiência da metodologia proposta para aperfeiçoar as previsões semanais das séries de vazão é avaliada a partir de dados observados e previstos de vazão de 28 dos principais reservatórios de regularização do país, conforme monitoramento realizado pelo ONS em seus boletins semanais de operação.

A fim de considerar as informações climáticas para o modelo mensal, são utilizados três índices climáticos como covariáveis no modelo estatístico PARX: índice NINO3, definido como a anomalia na temperatura média mensal da superfície do mar (TSM) na região do Pacífico tropical, especificamente na área geográfica entre $5^{\circ} \mathrm{N}$ e $5^{\circ} \mathrm{S}$ de latitude e entre $150^{\circ} \mathrm{W}$ e $90^{\circ} \mathrm{W}$ de longitude; índice SST2, construído a partir da média da anomalia de TSM sobre a região entre $12^{\circ} \mathrm{S}$ e $30^{\circ} \mathrm{S}$ de latitude e entre $40^{\circ} \mathrm{W}$ e $20^{\circ} \mathrm{W}$ de longitude; e o índice U1, indicador do vento zonal de baixa pressão $(700 \mathrm{mb})$ sobre a região entre $10^{\circ} \mathrm{S}$ e $20^{\circ} \mathrm{S}$ de latitude e entre $50^{\circ} \mathrm{W}$ e $35^{\circ} \mathrm{W}$ de longitude. Os dois primeiros indicadores captam os padrões do fenômeno El Niño Oscilação Sul (ENOS), cujas influências nas chuvas e nas vazões em todo o Brasil são bem conhecidas (CARDOSO; DIAS, 2006; COELHO et al., 2002; 
DIAZ; MARKGRAF, 2000; GRIMM et al., 2000; GRIMM, 2004; dentre outros). Maiores detalhes sobre a relação desses índices com as vazões do sistema hidroelétrico brasileiro são apresentados em Lima e Lall (2010b).

Para fins de compatibilização, tanto as séries médias mensais de vazões afluentes aos reservatórios quanto às séries mensais dos preditores climáticos cobrem o período de janeiro de 1949 a setembro de 2014. As séries semanais de vazões das usinas iniciam-se em janeiro de 2009, com término em setembro de 2014. Entre janeiro de 2009 e setembro de 2014, os valores das séries mensais foram compatibilizados com as informações das séries semanais, disponíveis nos relatórios do PMO.

Os índices climáticos foram obtidos a partir de dados interpolados das anomalias de TSM dos oceanos Pacífico e Atlântico (KAPLAN et al., 1998; REYNOLDS; SMITH, 1994) e são fornecidos pelo International Research Institute for Climate and Society (IRI, 2016a). Os dados de vento zonal de baixa pressão (700 mb) são oriundos da base NCEP-NCAR de reanálise e estão disponíveis em IRI (2016b).

\section{Previsões multiescala de vazão}

O ONS é responsável pela elaboração das previsões de afluência para todos os reservatórios do SIN. As previsões diárias são realizadas com o objetivo de completar a série de vazões da semana em curso (de sábado a quarta, adotam-se os valores de vazão observados e de quinta a domingo, as previsões diárias). São utilizadas previsões diárias elaboradas a partir dos modelos chuva-vazão do ONS ou elaboradas pelos agentes de geração. Se for necessário, utiliza-se o modelo estocástico PREVIVAZH (CEPEL, 2002b) processado pelo ONS para todos os aproveitamentos, ou, em último recurso, a média das vazões diárias observadas na semana (ONS, 2015). A partir das vazões semanais estimadas para a semana em curso, o ONS utiliza ou o modelo estocástico PREVIVAZ, que não incorpora qualquer informação climática, ou modelos que fazem uso de previsões de tempo a partir de modelos regionais de circulação atmosférica para elaborar a previsão de vazões semanais até duas semanas à frente. As previsões para a terceira semana em diante (até 6 semanas de antecedência) são realizadas pelo modelo PREVIVAZ.

As previsões semanais de vazões sintetizadas pelo ONS são determinísticas e podem ser obtidas a partir dos relatórios do Programa Mensal de Operação (PMO). Um modelo do tipo PARX para previsões de vazão mensais foi desenvolvido com objetivo de incorporar informação climática de larga escala nas previsões semanais de afluências. A conexão de ambas as escalas de previsão com objetivo de aperfeiçoar as previsões semanais é obtida por meio de um modelo de ponderação bayesiana, apresentado adiante.

\section{Previsões mensais de vazão}

Com objetivo de melhorar os modelos de previsão mensal, busca-se adicionar covariáveis $\mathbf{x}$ que respondam por parte da variabilidade de vazões. Exemplos de modelos semelhantes podem ser vistos em Lima e Lall (2010a,b) e Lima (2014). Seja então $q(t+\tau)$ a vazão de um determinado reservatório para o mês $t+\tau$ de certo ano. Os padrões de teleconexões (preditores climáticos) permitem modelar o processo de vazão como uma função de termos persistentes (vazões anteriores) e termos exógenos (preditores climáticos, por exemplo):

$q(t+)=f\left(q(t), x_{1}(t), x_{2}(t), x_{3}(t), \ldots \ldots ., x_{n}(t)\right)$

onde $t$ refere-se ao mês, $\tau$ é o horizonte futuro das previsões e $x_{1}, x_{2}, x_{3}, \ldots, x_{n}$ são os índices climáticos.

Uma abordagem comum para modelar a relação expressa na Equação 1 é considerar $f$ uma função linear e $q(t+\tau)$ uma variável aleatória normalmente distribuída com preditores e parâmetros que variam sazonalmente, sendo que a variância $\sigma^{2}$ não se mantém constante, pois depende do mês $t$ e do horizonte de previsão $\tau$ :

$$
q(t+) \sim N\left(\beta_{0 t}+\beta_{l t} q(t)+\beta_{2 t} x_{l}(t)+\beta_{3 t} x_{2}(t)+\beta_{4 t} x_{3}(t)+\ldots+\beta_{j t} x_{j}(t), \sigma_{t, \tau}^{2}\right)
$$

onde $q$ refere-se à vazão (afluência), t o tempo variando de 1 a 12 meses, $j$ é o número de covariáveis utilizadas (persistência e preditores climáticos), $\tau$ é o horizonte futuro de previsão, em meses, $\beta$ são os coeficientes da regressão, $x_{1}, x_{2}, \ldots ., x_{j}$ são covariáveis que podem ser índices climáticos, informações de precipitação, etc. e $\sigma_{t, \tau}^{2}$ é a variância em função do tempo $t$ e horizonte de previsão $\tau$.

\section{Modelo de ponderação bayesiana}

$\mathrm{Na}$ intenção de se definir a política operacional ótima do sistema elétrico brasileiro, de modo que a carga seja atendida a cada mês dentro do período de planejamento (até cinco anos) e ao custo total mínimo, o ONS utiliza um modelo computacional para otimização de longo e médio prazo, denominado NEWAVE (CEPEL, 2006) para definir a estratégia operacional mensal, agregando-se cada subsistema em um único reservatório equivalente. A função objetivo visa minimizar o valor esperado do custo operacional para todo o período. A estocasticidade associada às vazões futuras é representada por previsões mensais de vazões, feitas pelo modelo GEVAZP (CEPEL, 2002a), que utiliza abordagem do tipo periódica auto-regressiva. A principal saída do NEWAVE é a função de custo futuro, que é então utilizada nos modelos de otimização de curto prazo - DECOMP (CEPEL, 2013) e DESSEM (CEPEL, 2003) - para definir, até um ano a frente, o despacho ótimo de cada hidrelétrica, considerando restrições físicas e as vazões esperadas nas escalas diárias, semanais e mensais, fornecidas principalmente pelos modelos de previsão da família PREVIVAZ (CEPEL, 2004). As previsões de vazões diárias, feitas pelo PREVIVAZH, são basicamente uma desagregação das previsões semanais do PREVIVAZ, que por sua vez são utilizadas como condições iniciais para as previsões das vazões futuras pelo modelo GEVAZP até cinco anos à frente (mais detalhes em MACEIRA; PENNA; DAMÁZIO, 2006; COSTA et al., 2007).

Neste sentido, os modelos de previsão adotados pelo ONS estão conectados através de upscaling, onde as previsões nas pequenas escalas de tempo (semanais) são utilizadas para a maior escala de tempo (mensal). Aqui neste trabalho, propõe-se uma abordagem downscaling para conectar as previsões multiescala feitas pelo ONS. A ideia básica é melhorar as previsões de vazões semanais, sobretudo em lead times maiores do que dez dias a partir da agregação de informações que vão além da informação 
obtida pela persistência das vazões. Com isso, são incorporadas informações fornecidas pelas previsões mensais, o que, na ausência do modelo de previsão semanal, fornecem no contexto deste trabalho as melhores previsões semanais. Assim, cada semana dentro de determinado mês recebe o mesmo valor da previsão do modelo mensal para o referido mês. Uma forma possível de integrar as previsões consiste em ponderar as previsões feitas pelos modelos semanal e mensal por meio de um modelo de mistura finita, utilizando-se alguns pesos $w$ pré-definidos:

$$
q^{*}(t)=w_{1} q(t)+w_{2} Q+\varepsilon_{\tau}^{*}(t)
$$

onde: $q^{*}(t)$ é a previsão de vazão semanal após a ponderação bayesiana; $t=1, \ldots, 6$ é a antecedência semanal (lead time); $q(t)$ é a vazão prevista mensal (saída do modelo PARX); $Q$ é a vazão prevista semanal (saída dos modelos utilizados pelo ONS) e $\varepsilon_{\tau}^{*}(t)$ são os desvios das previsões.

Assume-se que $\varepsilon_{\tau}^{*}(t)$ possui distribuição normal com média zero e variância $\tau_{\varepsilon_{\tau}}^{2}(t)$. Os termos $w_{1}$ e $w_{2}$ representam os pesos bayesianos dos modelos mensal e semanal, respectivamente, cuja soma $w_{1}+w_{2}=1$.

Em um modelo com abordagem bayesiana de ponderações (por exemplo, HOETING et al., 1999; LINK; BARKER, 2006; VRUGT et al., 2008), a Equação 3 pode ser reescrita da forma:

$$
P_{r}(\text { Predição } \mid \text { Dados })=\sum_{i=1}^{2} P_{r}\left(\text { Predição } \mid \text { Dados }, M_{i}\right) \cdot P_{r}\left(M_{i} \mid \text { Dados }\right)
$$

onde o termo Predição refere-se à previsão semanal em alguma semana $\mathrm{t}, \mathrm{M}_{1}$ refere-se às previsões semanais obtidas dos relatórios do PMO, $\mathrm{M}_{2}$ é a previsão mensal (Equação 2) e $P_{r}($ Mi $\mid$ Dados $)=w_{i}$ é a probabilidade a posteriori para o modelo Mi (peso de cada modelo), dada por:

$$
P_{r}\left(M_{i} \mid \text { Dados }\right)=\frac{P_{r}\left(\operatorname{Dados} \mid M_{i}\right) P_{r}\left(M_{i}\right)}{\sum_{k=1}^{2} P_{r}\left(\operatorname{Dados} \mid M_{k}\right) P_{r}\left(M_{k}\right)}
$$

onde: $P_{r}\left(\right.$ Dados $\left.\mid M_{i}\right)$ é a verossimilhança do modelo i e $\operatorname{Pr}\left(\mathrm{M}_{\mathrm{k}}\right)$ corresponde à probabilidade a priori de que $\mathrm{M}_{\mathrm{k}}$ é o modelo verdadeiro. Assumiu-se nenhuma preferência pelos modelos, ou seja, $\operatorname{Pr}\left(\mathrm{M}_{1}\right)=\operatorname{Pr}\left(\mathrm{M}_{2}\right)=0,5$.

Como foram adotadas as saídas dos modelos semanais utilizados pelo ONS como insumo do modelo de ponderações, ou seja, dados do tipo determinísticos, o termo $P_{r}\left(\right.$ Predição $\mid$ Dados, $\left.M_{l}\right)$ é igual às previsões fornecidas pelo ONS. Para o modelo mensal, adotou-se o valor esperado das previsões considerando os três índices climáticos $\left[x_{1}, x_{2}, x_{3}\right]$ descritos anteriormente e a Equação 2:

$$
\begin{aligned}
& P_{r}\left(\text { Predição|Dados }, M_{2}\right)=\beta_{0}+\beta_{1 t} \cdot Q_{t-1}+ \\
& \beta_{2 t} x_{1}(t-1)+\beta_{3 t} x_{2}(t-1)+\beta_{4 t} x_{3}(t-1)
\end{aligned}
$$

onde os parâmetros associados a cada um dos reservatórios para cada mês t e horizonte $\tau$ são estimados de forma independente utilizando os dados históricos.

Os pesos desconhecidos $w$ foram estimados utilizando o algoritmo de otimização expectation maximiz̧ation (DEMPSTER, LAIRD; RUBIN, 1977; HASTIE et al., 2009), mas outras técnicas de amostragem poderiam ser utilizadas, como por exemplo, o método de Monte Carlo via Cadeias de Markov (VRUGT et al.,
2008; FRALEY et al., 2010; LIMA, 2014). Para o cálculo da verossimilhança $P_{r}\left(\right.$ Dados $\left.\mid M_{i}\right)$ foi escolhida uma distribuição normal para testar a metodologia proposta em função da característica da relação funcional entre observações e previsões.

Ressalta-se também que o modelo proposto para conectar as previsões multiescala não precisa ser necessariamente restrito aos modelos aqui apresentados. Ao invés de se utilizar dados determinísticos, previsões semanais poderiam ser feitas por meio de modelos de base física, por exemplo, utilizando um modelo de circulação atmosféricas para previsões de chuvas acoplado a um modelo hidrológico que transforme as previsões de chuva em previsões de vazão (por exemplo, veja SILVA et al., 2006, 2007; FADIGA JUNIOR et al., 2008; CASTANHARO et al., 2007; CATALDI et al., 2007; COLLISCHONN et al., 2007). Assim, a distribuição dos resultados das previsões do modelo chuva-vazão poderia ser substituída em $P_{r}\left(\right.$ Predição $\mid$ Dados,$\left.M_{l}\right)$.

\section{RESULTADOS E DISCUSSÃO}

\section{Resultados das previsões mensais de vazão}

Os dados dos preditores climáticos e de vazão foram primeiramente divididos em um conjunto de calibração (abrangendo o período de 1949-2008), onde os parâmetros do modelo são estimados, e um conjunto de validação (2009-2014), que avalia o desempenho do modelo. O longo período de calibração adotado garante que todos os reservatórios tenham passado por uma variedade de condições de vazão (tanto em condições normais, como abaixo e acima das médias). Assim, ao experimentar as diversas transições de períodos secos e úmidos, espera-se que o período de calibração escolhido minimize a dependência das competências do modelo e das estimativas de parâmetros.

A avaliação do poder de previsão do modelo mensal PARX foi efetuada por meio do indicador de qualidade de Nash-Sutcliffe (NS), conforme a Equação 7:

$$
N S=1-\frac{\sum_{t=1}^{n}\left(P_{t}-O_{t}\right)^{2}}{\sum_{t=1}^{n}\left(O_{t}-\bar{O}\right)^{2}}
$$

onde $n$ é o número de intervalos de tempo; $O_{t}$ a vazão observada no intervalo de tempo t; $\bar{O}$ a média das vazões observadas nos intervalos de tempo de 1 a n e $P_{t}$ a vazão prevista no intervalo de tempo $t$.

$\mathrm{O}$ índice NS pode assumir valores no intervalo $(-\infty, 1]$, sendo que NS=1 corresponde à previsão perfeita das vazões no período. Quando NS $<0$ entende-se ser preferível utilizar o valor médio das observações do que os resultados previstos pelo modelo.

As Figuras 1 a 7 apresentam um comparativo entre os resultados do Indicador NS para os modelos mensais PARX e PAR (nenhuma informação climática) com antecedência de um e dois meses para as previsões mensais dos vinte e oito reservatórios do estudo.

Embora haja uma natural redução do desempenho do modelo à medida que a antecedência mensal aumenta, verifica-se que o indicador NS do modelo mensal PARX, que utiliza indicadores climáticos como preditores exógenos, é superior aos resultados do modelo PAR, sobretudo para previsões com um mês de antecedência. 


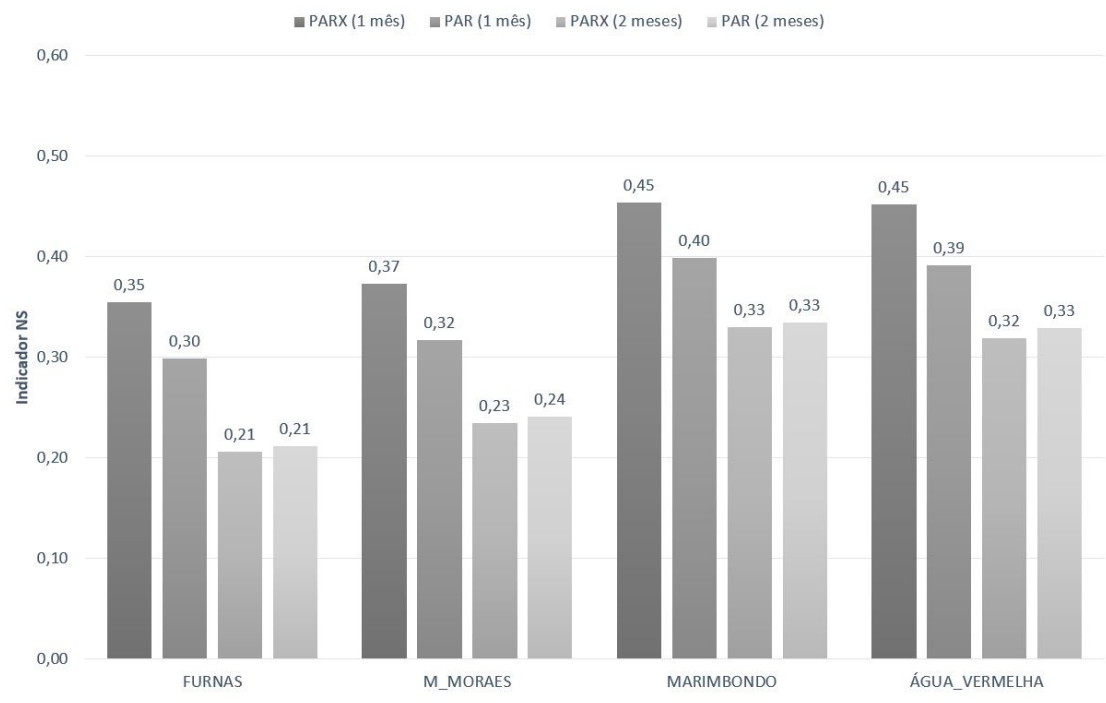

Figura 1. Comparativo entre os indicadores de Nash-Sutcliffe (NS) dos modelos mensais PARX e PAR com antecedência de um e dois meses para as usinas do rio Grande.

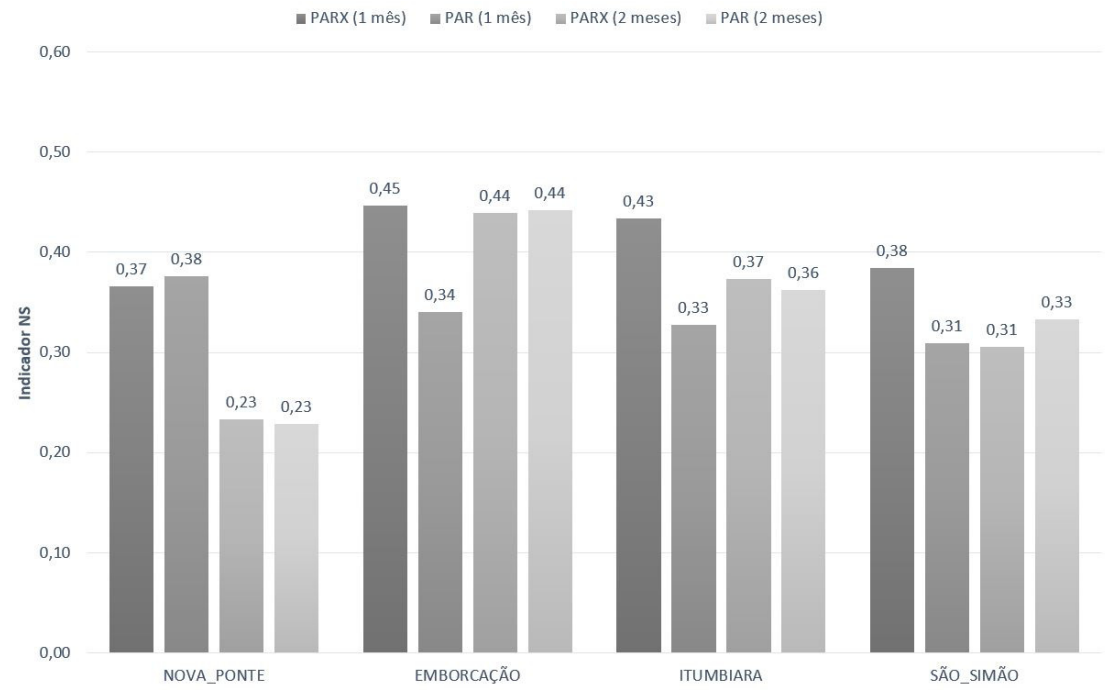

Figura 2. Assim como na Figura 1, mas para as usinas do rio Paranaíba.

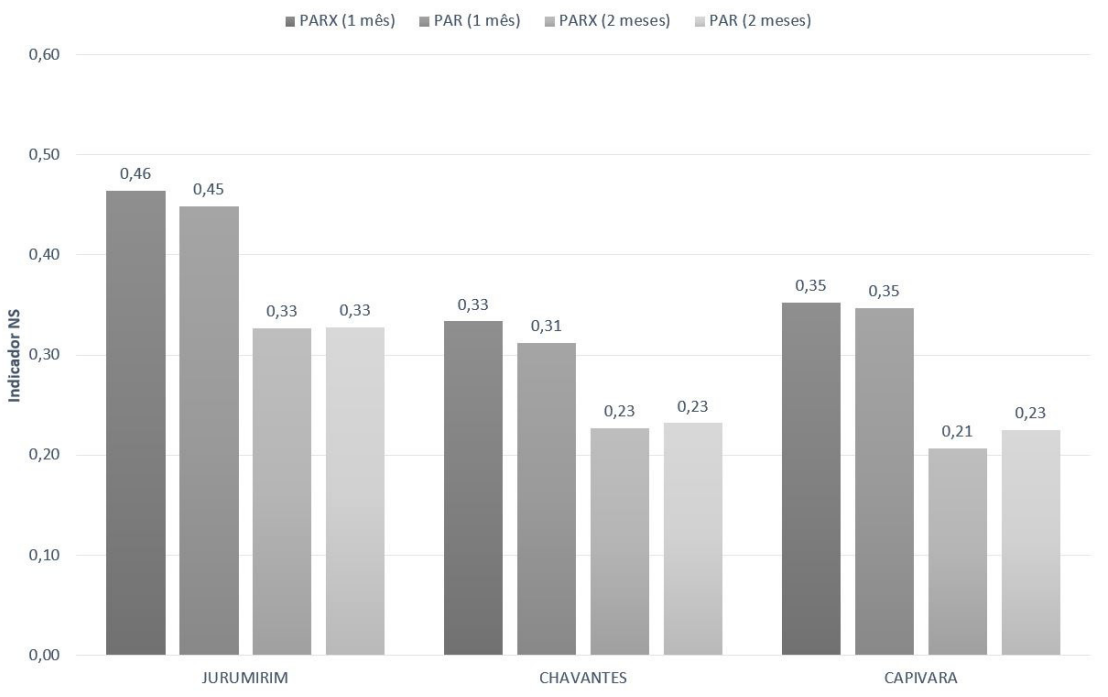

Figura 3. Assim como na Figura 1, mas para as usinas do rio Paranapanema. 


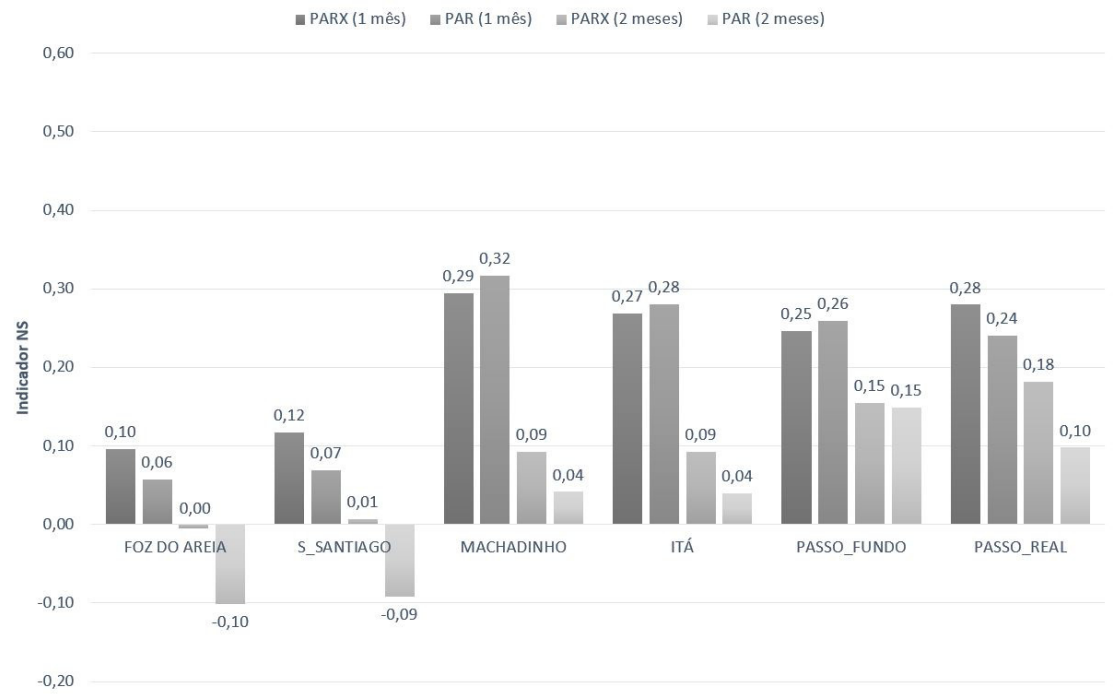

Figura 4. Assim como na Figura 1, mas para as usinas dos rios Iguaçu, Uruguai e Jacuí.

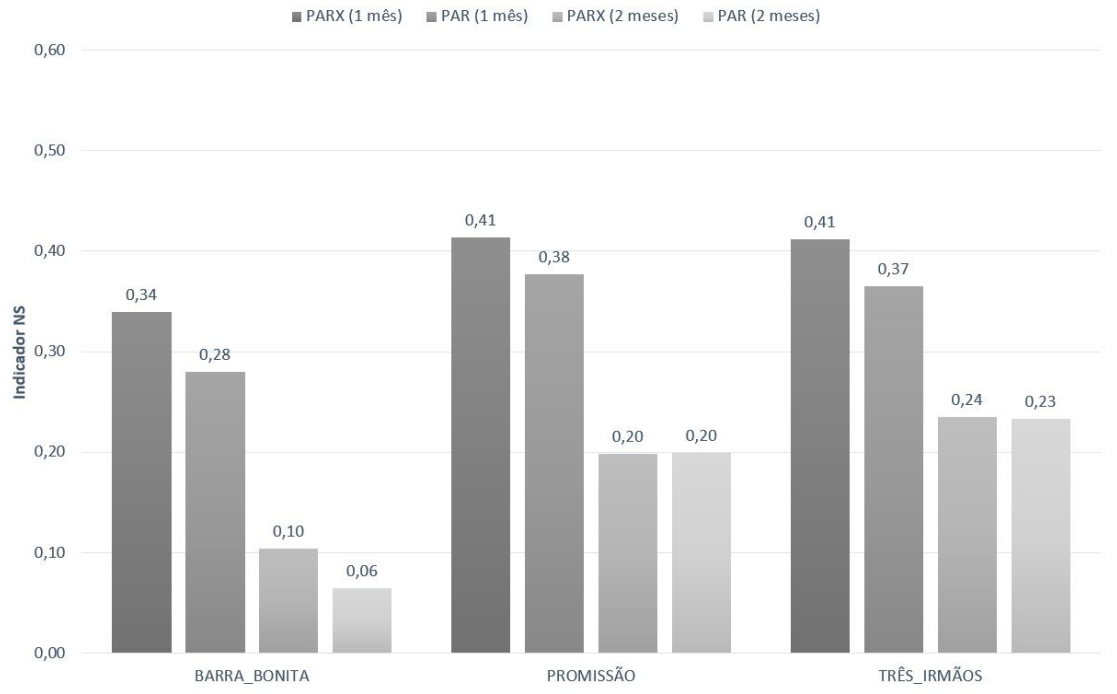

Figura 5. Assim como na Figura 1, mas para as usinas do rio Tietê.

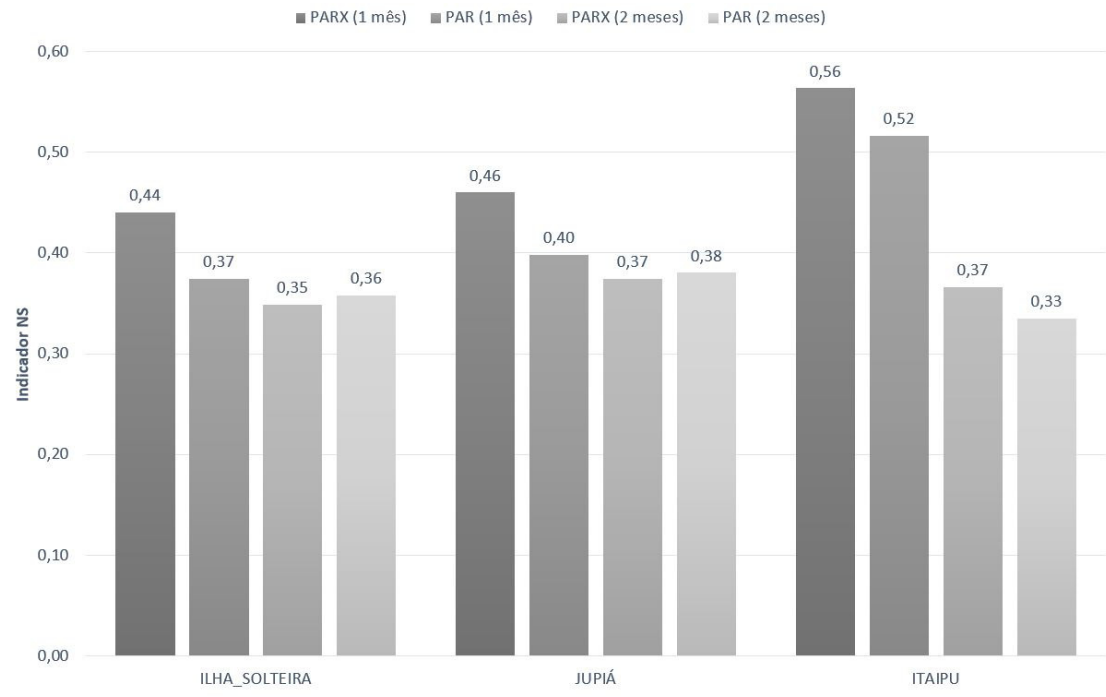

Figura 6. Assim como na Figura 1, mas para as demais usinas da cascata do rio Paraná. 


\section{Resultados das ponderações bayesianas}

A distribuição espacial dos pesos obtidos para os modelos mensais em função da antecedência (lead time) semanal é apresentada nas Figuras 8 a 10. Os círculos em verde representam os pesos dos modelos mensais que não superaram os pesos semanais (menores do que 0,5 ); os círculos na cor vermelha indicam o contrário (pesos mensais maiores do que 0,5$)$.

A Figura 8 apresenta os resultados para as primeiras duas semanas de antecedência. Em virtude da persistência das vazões, verifica-se que os modelos semanais sobrepõem-se aos mensais para a antecedência de uma semana em todos os reservatórios testados. Com antecedência de duas semanas, os modelos semanais ainda são soberanos nas ponderações, exceção feita às previsões dos reservatórios de Jurumirim, Passo Fundo e Passo Real (OLIVEIRA, 2015).
A Figura 9 ilustra a distribuição espacial dos pesos mensais para a terceira e quarta semanas de antecedência. Nota-se um equilíbrio entre os reservatórios que utilizam os modelos semanais e mensais, sobretudo quando a antecedência atinge quatro semanas. Os modelos semanais são preponderantes nas usinas localizadas acima da latitude $20^{\circ} \mathrm{S}$ e os modelos mensais, nas usinas abaixo dessa linha divisória, indicando que essas usinas mais ao sul possuem melhor resposta às previsões com o modelo mensal (ou seja, possuem um sinal climático mais influente nas previsões).

A Figura 10 apresenta a distribuição dos pesos mensais para a quinta e sexta semana de antecedência. Nota-se, em alguns casos, a recuperação dos modelos semanais na ponderação bayesiana dos modelos. Essa constatação pode ser consequência da redução do desempenho dos modelos mensais na transição do lead time de um mês para dois meses, conforme ilustrado anteriormente nas Figuras 1 a 7 . Outra justificativa pode advir da grande redução do

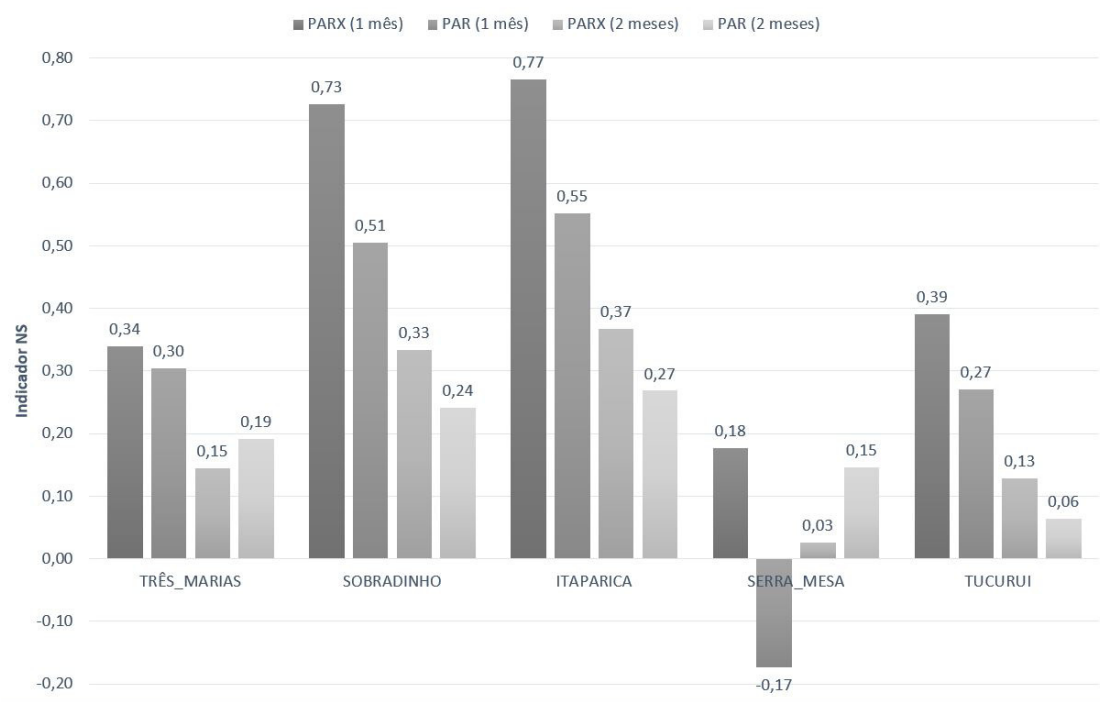

Figura 7. Assim como na Figura 1, mas para as usinas dos rios São Francisco e Tocantins.

diferença DM (1 sem. antec.)

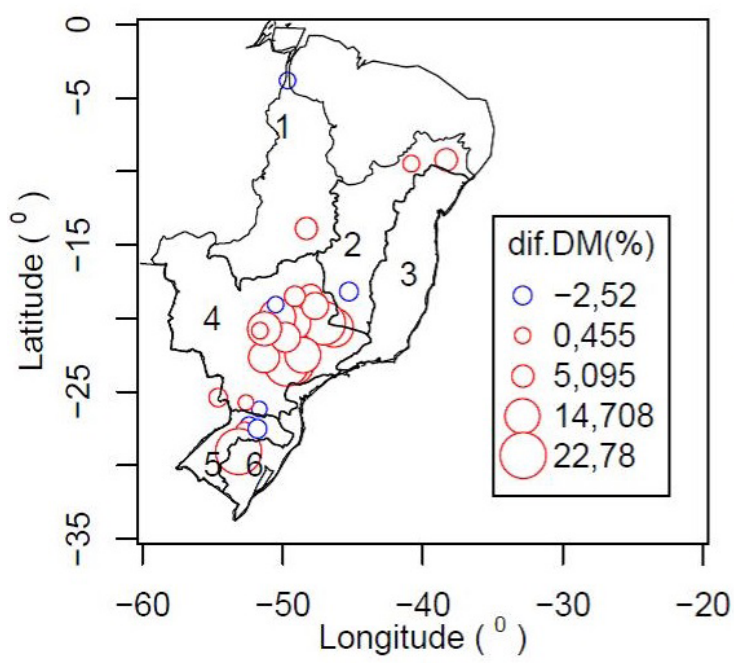

diferença DM (2 sem. antec.)

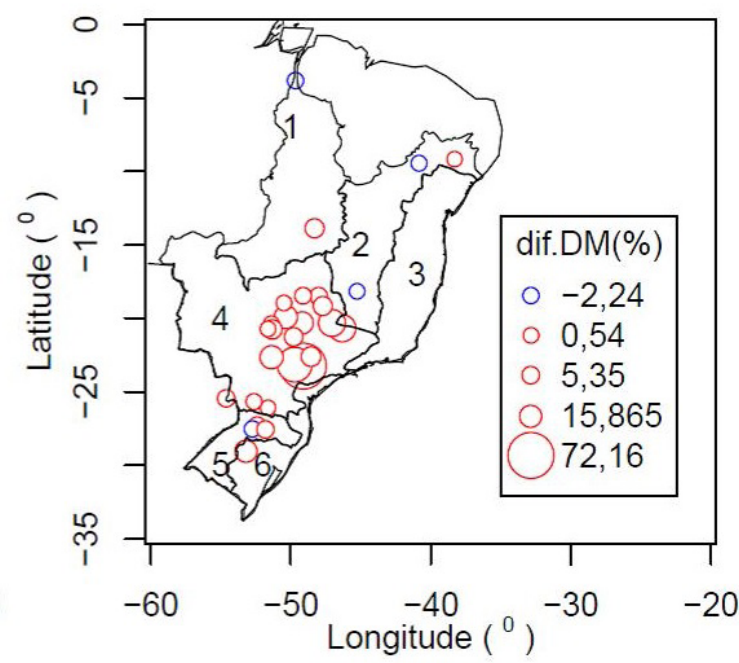

Figura 8. Distribuição espacial dos pesos dos modelos de previsão mensal nos 28 reservatórios analisados para previsões com antecedências de uma (painel da esquerda) e duas (painel da direita) semanas. 
diferença DM (3 sem. antec.)

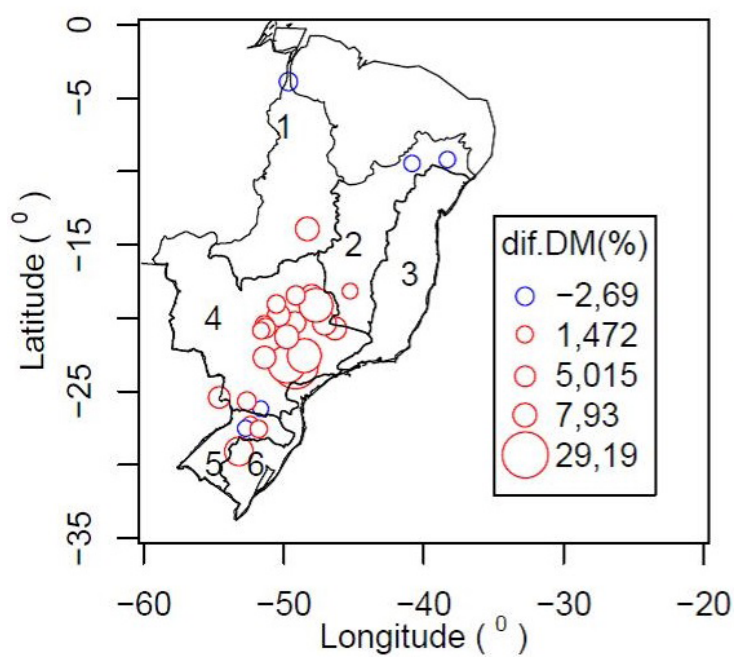

diferença DM (4 sem. antec.)

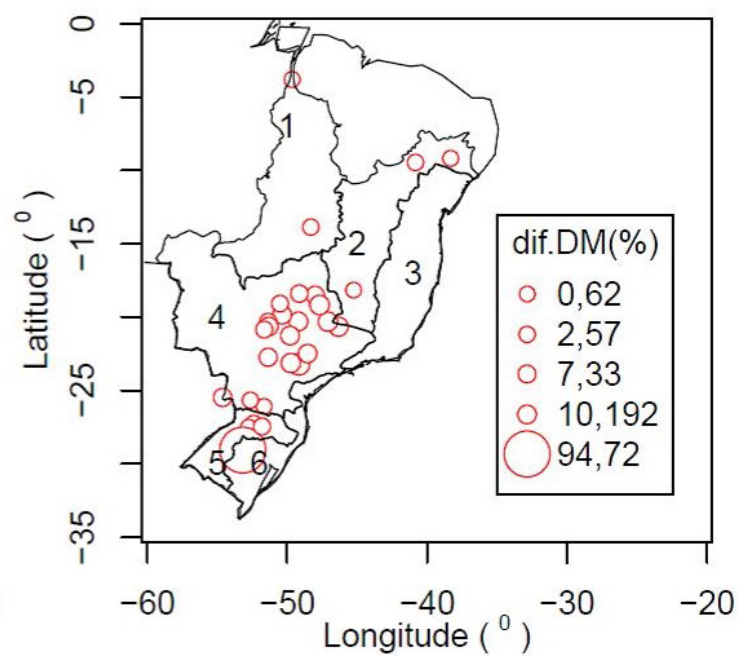

Figura 9. Como na Figura 8, mas para previsões realizadas com três (painel da esquerda) e quatro (painel da direita) semanas de antecedência.

diferença DM (5 sem. antec.)

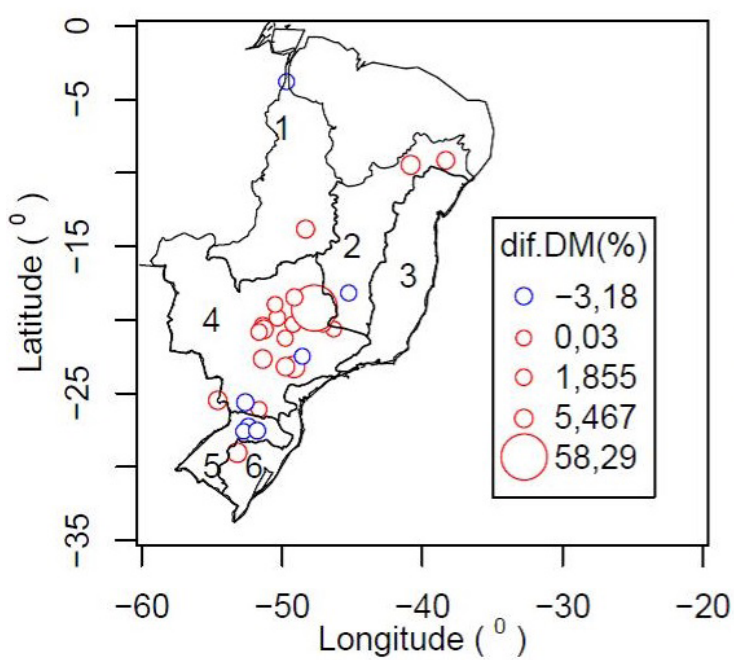

diferença DM (6 sem. antec.)

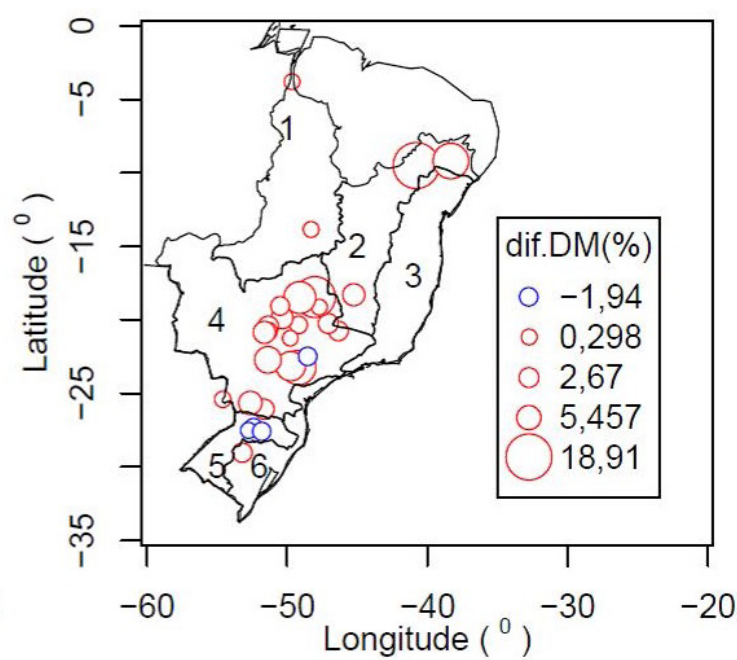

Figura 10. Como na Figura 8, mas para previsões realizadas com cinco (painel da esquerda) e seis (painel da direita) semanas de antecedência.

número de amostras para os modelos com cinco e seis semanas de antecedência. Amostras de menor tamanho possuem menos informação nos dados, com isso os valores das probabilidades a posteriori dos modelos (PMP) aproximam-se dos valores a priori, auferindo menores ganhos às ponderações que em modelos com maior número de amostras (GIBBONS et al., 2008).

Para a avaliação da qualidade dos modelos semanais, adotou-se o indicador Distância Multicritério (DM), que é composto pelos indicadores NS e MAPE (erro médio percentual absoluto). O índice DM, adotado pelo ONS em suas avaliações, representa a distância euclidiana ao ponto ótimo, no caso $(0,0)$, conforme equação a seguir (ONS, 2015):

$D M=\sqrt{(1-N S)^{2}+M A P E^{2}}$ onde:

$M A P E=\frac{1}{n} \sum_{t=1}^{n}\left|\frac{\left(O_{t}-P_{t}\right)}{O_{t}}\right|$

As Figuras 11 a 13 apresentam as diferenças percentuais do indicador DM. Os valores em vermelho indicam que as diferenças entre os indicadores das previsões semanais utilizadas pelo ONS e das previsões BMA são positivas, ou seja, os resultados da aplicação da técnica BMA são superiores às previsões semanais fornecidas pelo ONS. Assim, constata-se que na quase totalidade dos casos houve melhora após as ponderações. Os resultados constantes das Figuras 11 a 13 estão detalhados na Tabela 1.

No intuito de verificar se as diferenças entre as medidas de desempenho dos modelos devem-se somente à variabilidade 
pesos mensais (1 sem. antec.)

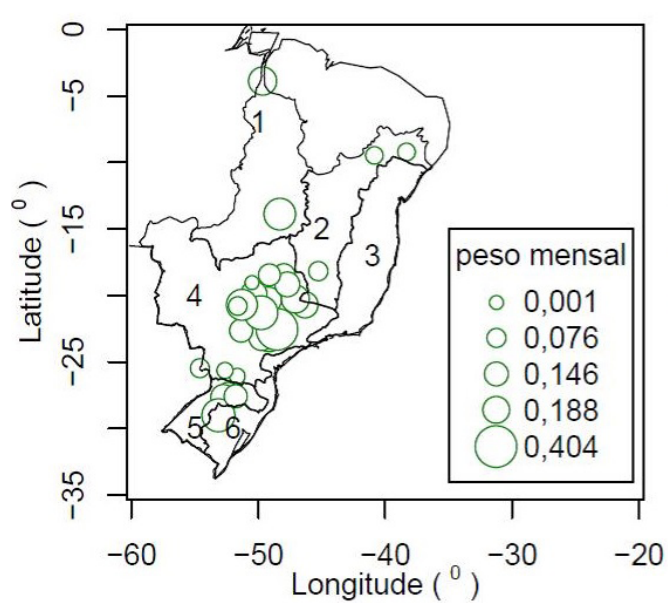

pesos mensais ( 2 sem. antec.)

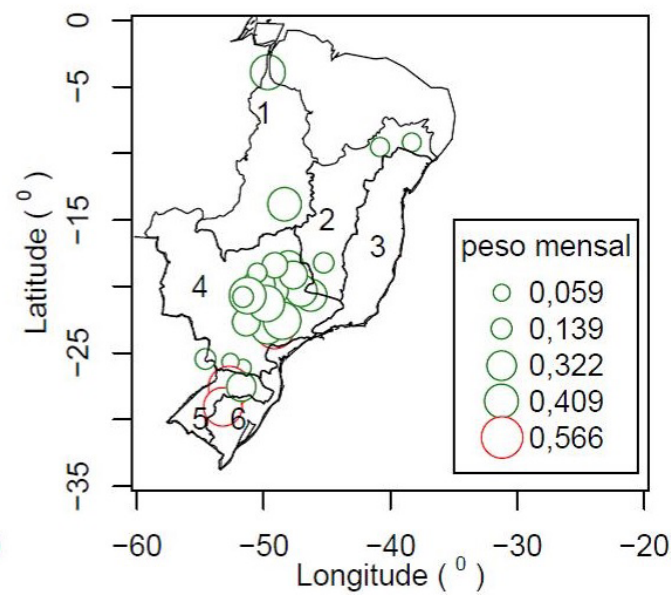

Figura 11. Resultados das diferenças percentuais entre o indicador DM das previsões semanais realizadas pelo ONS e das previsões BMA com uma (painel da esquerda) e duas (painel da direita) semanas de antecedência.

pesos mensais ( 3 sem. antec.)

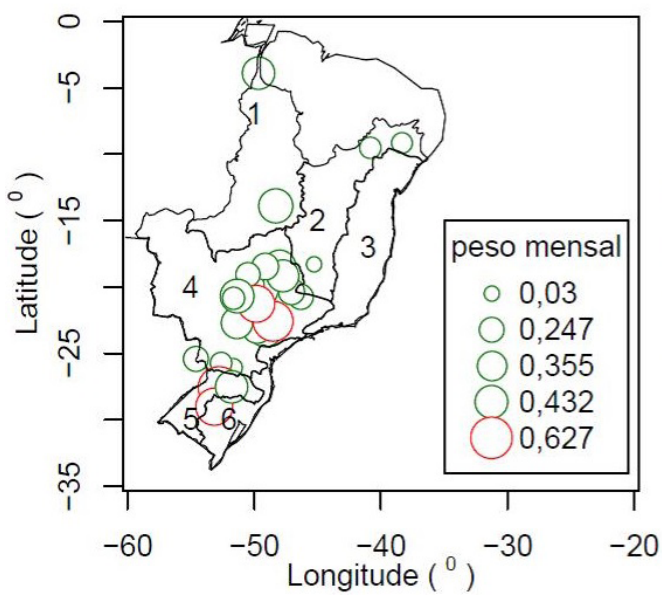

pesos mensais ( 4 sem. antec.)

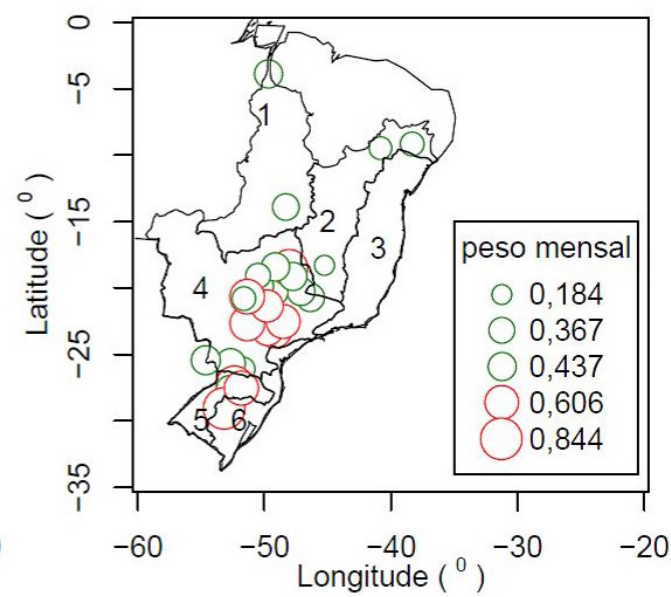

Figura 12. Como na Figura 11, mas para as previsões realizadas com três (painel da esquerda) e quatro (painel da direita) semanas de antecedência.

pesos mensais ( 5 sem. antec.)

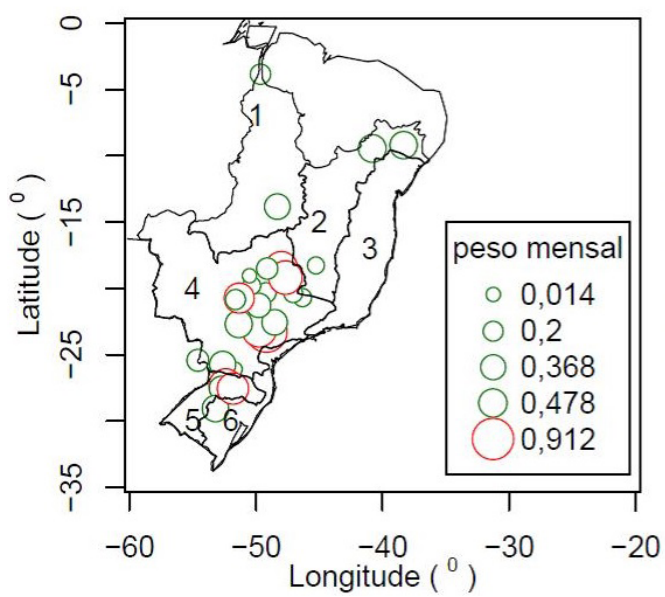

pesos mensais (6 sem. antec.)

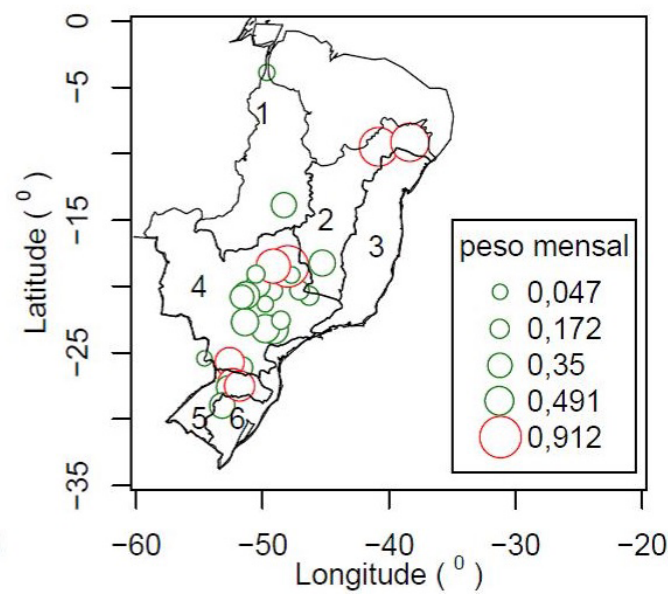

Figura 13. Como na Figura 11, mas para as previsões realizadas com cinco (painel da esquerda) e seis (painel da direita) semanas de antecedência. 
Tabela 1. Diferenças percentuais para o indicador DM.

\begin{tabular}{|c|c|c|c|c|c|c|c|}
\hline & \multicolumn{6}{|c|}{ Antecedência Semanal } & \multirow{2}{*}{ Bacia } \\
\hline Indicador DM & 1 & 2 & 3 & 4 & 5 & 6 & \\
\hline FURNAS & $17,3 \%$ & $28,0 \%$ & $7,2 \%$ & $11,7 \%$ & $0,4 \%$ & $2,6 \%$ & \multirow{4}{*}{ Grande } \\
\hline M. MORAES & $20,8 \%$ & $27,6 \%$ & $8,0 \%$ & $12,2 \%$ & $0,8 \%$ & $2,8 \%$ & \\
\hline MARIMBONDO & $14,6 \%$ & $16,2 \%$ & $6,3 \%$ & $10,5 \%$ & $1,4 \%$ & $1,3 \%$ & \\
\hline A. VERMELHA & $15,8 \%$ & $18,6 \%$ & $6,9 \%$ & $9,8 \%$ & $2,0 \%$ & $3,9 \%$ & \\
\hline EMBORCACAO & $6,3 \%$ & $5,9 \%$ & $7,3 \%$ & $9,0 \%$ & $3,7 \%$ & $15,8 \%$ & \multirow{4}{*}{ Paranaíba } \\
\hline NOVA PONTE & $8,6 \%$ & $9,0 \%$ & $17,7 \%$ & $13,1 \%$ & $58,3 \%$ & $0,3 \%$ & \\
\hline ITUMBIARA & $3,9 \%$ & $3,2 \%$ & $3,6 \%$ & $6,3 \%$ & $2,9 \%$ & $10,3 \%$ & \\
\hline SAO.SIMAO & $-0,7 \%$ & $0,5 \%$ & $2,8 \%$ & $3,8 \%$ & $0,4 \%$ & $2,0 \%$ & \\
\hline JURUMIRIM & $17,5 \%$ & $72,2 \%$ & $29,2 \%$ & $19,2 \%$ & $11,4 \%$ & $11,8 \%$ & \multirow{3}{*}{ Paranapanema } \\
\hline CHAVANTES & $21,5 \%$ & $45,8 \%$ & $21,1 \%$ & $12,0 \%$ & $5,6 \%$ & $8,8 \%$ & \\
\hline CAPIVARA & $11,6 \%$ & $18,3 \%$ & $6,8 \%$ & $8,4 \%$ & $5,7 \%$ & $7,0 \%$ & \\
\hline FOZ DO AREIA & $-0,1 \%$ & $0,0 \%$ & $-0,1 \%$ & $1,0 \%$ & $0,1 \%$ & $2,9 \%$ & \multirow{2}{*}{ Iguaçu } \\
\hline SALTO SANTIAGO & $0,0 \%$ & $1,5 \%$ & $3,1 \%$ & $2,0 \%$ & $-3,2 \%$ & $5,0 \%$ & \\
\hline MACHADINHO & $-2,5 \%$ & $4,7 \%$ & $1,9 \%$ & $5,0 \%$ & $-2,4 \%$ & $-1,8 \%$ & \multirow{3}{*}{ Uruguai } \\
\hline ITA & $-1,5 \%$ & $4,6 \%$ & $1,5 \%$ & $4,7 \%$ & $-2,4 \%$ & $-1,7 \%$ & \\
\hline PASSO FUNDO & $1,0 \%$ & $-2,2 \%$ & $-0,6 \%$ & $2,4 \%$ & $-0,1 \%$ & $-0,4 \%$ & \\
\hline PASSO REAL & $22,8 \%$ & $15,8 \%$ & $12,6 \%$ & $94,7 \%$ & $7,6 \%$ & $2,4 \%$ & Jacuí \\
\hline BARRA.BONITA & $15,2 \%$ & $10,2 \%$ & $17,7 \%$ & $9,5 \%$ & $-0,6 \%$ & $-1,9 \%$ & \multirow{3}{*}{ Tietê } \\
\hline PROMISSAO & $10,8 \%$ & $7,5 \%$ & $8,3 \%$ & $10,1 \%$ & $1,0 \%$ & $0,1 \%$ & \\
\hline TRES IRMAOS & $13,8 \%$ & $9,4 \%$ & $4,2 \%$ & $9,6 \%$ & $6,4 \%$ & $0,9 \%$ & \\
\hline ILHA.SOLTEIRA & $0,6 \%$ & $0,7 \%$ & $2,8 \%$ & $5,1 \%$ & $2,4 \%$ & $3,1 \%$ & \multirow{3}{*}{ Paraná } \\
\hline JUPIA & $1,1 \%$ & $0,6 \%$ & $1,4 \%$ & $4,6 \%$ & $1,7 \%$ & $4,2 \%$ & \\
\hline ITAIPU & $2,3 \%$ & $4,8 \%$ & $5,8 \%$ & $8,6 \%$ & $5,4 \%$ & $0,6 \%$ & \\
\hline TRES MARIAS & $-2,4 \%$ & $-0,4 \%$ & $0,2 \%$ & $0,6 \%$ & $-1,1 \%$ & $4,2 \%$ & \multirow{3}{*}{ São Francisco } \\
\hline SOBRADINHO & $1,0 \%$ & $-1,3 \%$ & $-0,8 \%$ & $2,5 \%$ & $6,9 \%$ & $18,9 \%$ & \\
\hline ITAPARICA & $5,2 \%$ & $0,3 \%$ & $-0,9 \%$ & $1,7 \%$ & $4,2 \%$ & $12,5 \%$ & \\
\hline SERRA DA MESA & $5,0 \%$ & $8,7 \%$ & $7,9 \%$ & $2,6 \%$ & $4,7 \%$ & $0,3 \%$ & \multirow{2}{*}{ Tocantins } \\
\hline TUCURUI & $-0,6 \%$ & $-2,2 \%$ & $-2,7 \%$ & $1,6 \%$ & $-0,3 \%$ & $0,2 \%$ & \\
\hline valores médios & $7,5 \%$ & $11,0 \%$ & $6,4 \%$ & $10,1 \%$ & $4,4 \%$ & $4,1 \%$ & \\
\hline
\end{tabular}

amostral, foi testada a hipótese nula de que as saídas dos modelos semanais antes e após a ponderação BMA possuem iguais acurácias de precisão utilizando a métrica de Diebold-Mariano, cuja estatística do teste converge para uma distribuição normal padrão (DIEBOLD; MARIANO, 1995).

A estatística do teste baseia-se na média e no desvio da diferença entre os erros das previsões dos dois modelos concorrentes, em que a estimativa da variância representa a correlação do erro de previsão de acordo com o lead time da previsão. A precisão de cada previsão é medida por funções de perda. Aqui, adotou-se a função de perda quadrática.

O resultado dos testes de hipóteses (valor-p) em função do lead time semanal das previsões encontra-se resumido na Tabela 2. As células na cor cinza (valor-p iguais ou menores do que o nível de significância $\alpha=0,10$ ) indicam os casos em que a hipótese nula foi rejeitada, ao nível de significância de 10\%. Depreende-se da Tabela 2 que em 102 das 168 previsões analisadas (seis antecedências semanais para cada um dos 28 reservatórios) rejeitou-se a hipótese nula, ao nível de significância de 10\%. A discretização dos resultados de acordo com a antecedência semanal das previsões, efetuada na última linha da Tabela 2 mostra que os resultados são melhores nas quatro primeiras semanas, com índices de rejeição da hipótese nula variando entre $71,4 \%$ (primeira e quarta semana) e $82,1 \%$ (segunda semana de antecedência).

\section{Resultados por bacia hidrográfica}

As previsões das usinas foram avaliadas tanto individualmente como por bacia hidrográfica. Ao todo, dez bacias distintas participaram dos estudos, representadas pelos vinte e oito principais reservatórios de acumulação do país. Uma apresentação e interpretação mais detalhada dos resultados por bacia é oferecida em Oliveira (2015).

A bacia do rio Paranaíba, por exemplo, contempla uma série de reservatórios em cascata, ilustrada na Figura 14. Nessa bacia, foram avaliadas as previsões de quatro de seus reservatórios: as Usinas Hidrelétricas (UHE) Nova Ponte, Emborcação, Itumbiara e São Simão, com áreas de drenagem variando de $15.480 \mathrm{~km}^{2}$, na primeira das usinas, a $171.474 \mathrm{~km}^{2}$, na última delas.

Nas Figuras 15 a 18 apresenta-se o comportamento dos indicadores das quatro usinas avaliadas no Paranaíba. O painel superior compara os resultados do indicador DM para as previsões semanais realizadas pelo ONS (curva na cor cinza) e para as previsões BMA (na cor laranja); o painel inferior apresenta o comportamento dos pesos semanais (curva na cor azul) e mensais (cor vermelha) no decorrer das previsões.

$\mathrm{Na}$ análise das quatro usinas do Paranaíba, destaca-se que a maior diferença obtida entre o indicador DM das previsões semanais antes e após a aplicação da técnica BMA ocorreu nas UHE Nova Ponte e Emborcação, situadas no trecho correspondente ao alto Paranaíba, e que utilizaram os modelos mensais com maior intensidade nas ponderações. 
Tabela 2. Valor-p do teste de Diebold-Mariano (células em cinza onde ocorre a rejeição da hipótese nula de nenhum ganho do modelo BMA, ao nível de significância $\alpha=10 \%)$.

\begin{tabular}{|c|c|c|c|c|c|c|}
\hline Reservarório & & & de Diel & iano (v & & \\
\hline ANTECED. SEMANAL & 1 & 2 & 3 & 4 & 5 & 6 \\
\hline FURNAS & 0,00 & 0,01 & 0,01 & 0,02 & 0,47 & 0,16 \\
\hline M. MORAES & 0,00 & 0,01 & 0,01 & 0,03 & 0,36 & 0,15 \\
\hline MARIMBONDO & 0,01 & 0,01 & 0,07 & 0,02 & 0,23 & 0,33 \\
\hline ÁGUA VERMELHA & 0,00 & 0,01 & 0,07 & 0,04 & 0,32 & 0,30 \\
\hline EMBORCAÇÃO & 0,01 & 0,05 & 0,03 & 0,07 & 0,14 & 0,09 \\
\hline NOVA PONTE & 0,03 & 0,05 & 0,02 & 0,10 & 0,05 & 0,42 \\
\hline ITUMBIARA & 0,07 & 0,07 & 0,04 & 0,04 & 0,06 & 0,11 \\
\hline SÃO SIMÃO & 0,97 & 0,23 & 0,09 & 0,09 & 0,26 & 0,24 \\
\hline JURUMIRIM & 0,01 & 0,02 & 0,02 & 0,01 & 0,01 & 0,07 \\
\hline CHAVANTES & 0,00 & 0,01 & 0,02 & 0,03 & 0,08 & 0,05 \\
\hline CAPIVARA & 0,00 & 0,01 & 0,06 & 0,01 & 0,05 & 0,05 \\
\hline FOZ DO AREIA & 0,28 & 0,11 & 0,45 & 0,23 & 0,56 & 0,14 \\
\hline SALTO SANTIAGO & 0,53 & 0,04 & 0,13 & 0,31 & 0,77 & 0,09 \\
\hline MACHADINHO & 0,59 & 0,07 & 0,11 & 0,04 & 0,57 & 0,56 \\
\hline ITÁ & 0,42 & 0,06 & 0,12 & 0,03 & 0,53 & 0,54 \\
\hline PASSO FUNDO & 0,01 & 0,05 & 0,05 & 0,23 & 0,42 & 0,33 \\
\hline PASSO REAL & 0,02 & 0,00 & 0,01 & 0,15 & 0,03 & 0,14 \\
\hline BARRA BONITA & 0,00 & 0,01 & 0,02 & 0,02 & 0,49 & 0,82 \\
\hline PROMISSÃO & 0,00 & 0,04 & 0,02 & 0,01 & 0,42 & 0,55 \\
\hline TRÊS IRMÃOS & 0,00 & 0,03 & 0,06 & 0,02 & 0,14 & 0,42 \\
\hline ILHA SOLTEIRA & 0,33 & 0,28 & 0,20 & 0,15 & 0,28 & 0,17 \\
\hline JUPIÁ & 0,31 & 0,33 & 0,24 & 0,14 & 0,32 & 0,14 \\
\hline ITAIPU & 0,10 & 0,00 & 0,00 & 0,00 & 0,03 & 0,23 \\
\hline TRÊS MARIAS & 0,21 & 0,26 & 0,15 & 0,48 & 0,82 & 0,15 \\
\hline SOBRADINHO & 0,07 & 0,03 & 0,06 & 0,06 & 0,02 & 0,03 \\
\hline ITAPARICA & 0,02 & 0,01 & 0,05 & 0,08 & 0,06 & 0,08 \\
\hline SERRA DA MESA & 0,02 & 0,01 & 0,03 & 0,12 & 0,10 & 0,21 \\
\hline TUCURUI & 0,03 & 0,10 & 0,07 & 0,01 & 0,07 & 0,34 \\
\hline rejeição da hip. H0 & $71,4 \%$ & $82,1 \%$ & $75,0 \%$ & $71,4 \%$ & $39,3 \%$ & $25,0 \%$ \\
\hline
\end{tabular}

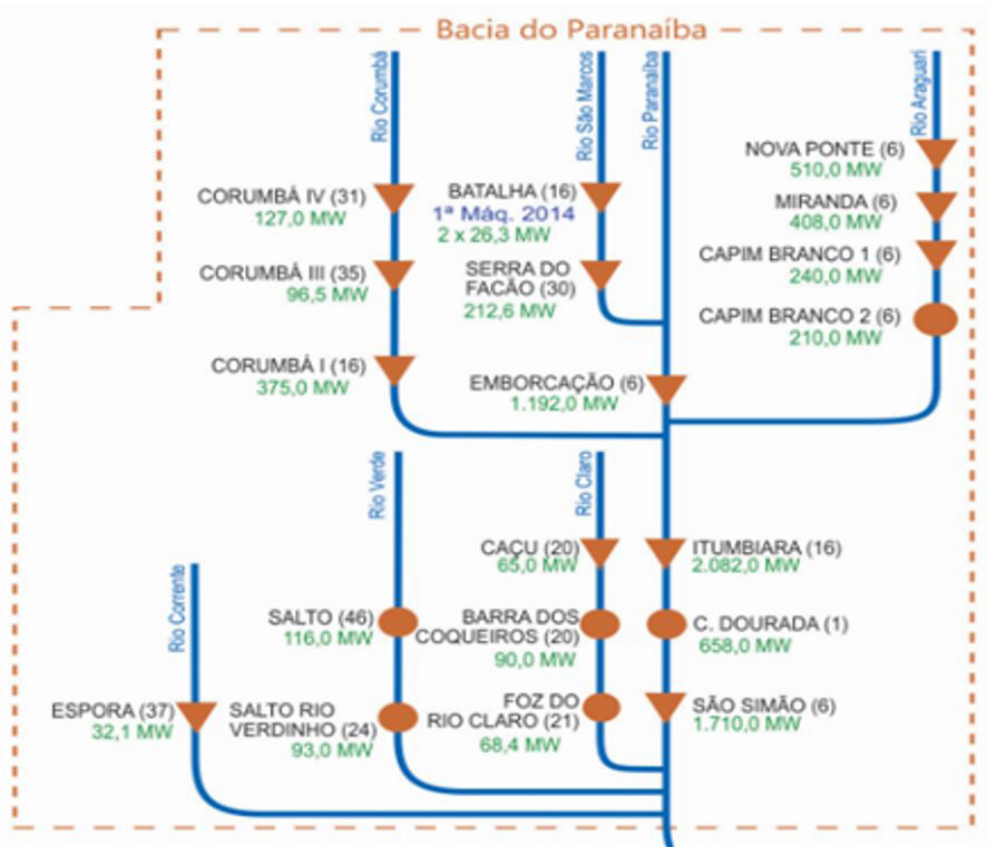

Figura 14. Esquema topológico das usinas do Paranaíba. Fonte: ONS (2015). 
A Figura 15 apresenta os indicadores para a UHE Nova Ponte, única das quatro usinas que não se situa propriamente no rio Paranaíba (seu rio, o Araguari, desagua a jusante da UHE Emborcação). Verifica-se no painel superior uma significativa diferença entre as curvas, o que demonstra o alto desempenho das ponderações BMA (curva laranja) nessa usina, quando comparadas com as previsões originais fornecidas pelo ONS (cinza), lembrando que para o indicador DM, quanto mais próximo de zero, melhor o resultado. Nota-se, no painel inferior, que a utilização do peso mensal é crescente até a quinta semana, onde atinge seu pico (60\% de utilização).

Quanto à UHE Emborcação, a primeira usina analisada na cascata do Paranaíba, com área de drenagem de $29.050 \mathrm{~km}^{2}$, os resultados de seus indicadores encontram-se na Figura 16. Verifica-se que a superação do peso semanal pelo mensal ocorreu na transição da terceira para a quarta semana.

A Figura 17 apresenta o resultado dos indicadores da UHE Itumbiara, que possui área de drenagem de $94.728 \mathrm{~km}^{2}$ e está situada na porção média do rio Paranaíba. Quanto à distribuição dos pesos, verifica-se que a superação do peso semanal pelo mensal ocorre na última semana, representando um deslocamento em relação ao verificado na UHE Emborcação. Em consequência, houve redução na diferença entre os indicadores BMA semanais antes e após as ponderações (menores diferenças entre as curvas cinza e laranja no painel superior).
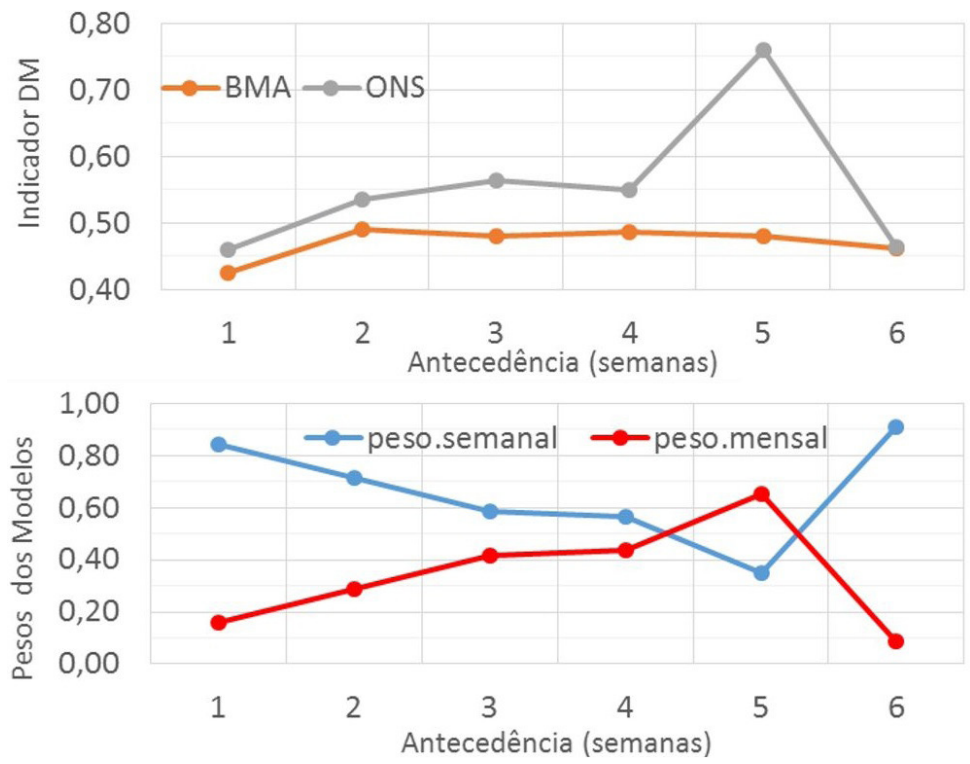

Figura 15. Indicador DM (painel superior) e peso dos modelos (painel inferior) em função do tempo de antecedência das previsões para a UHE Nova Ponte.
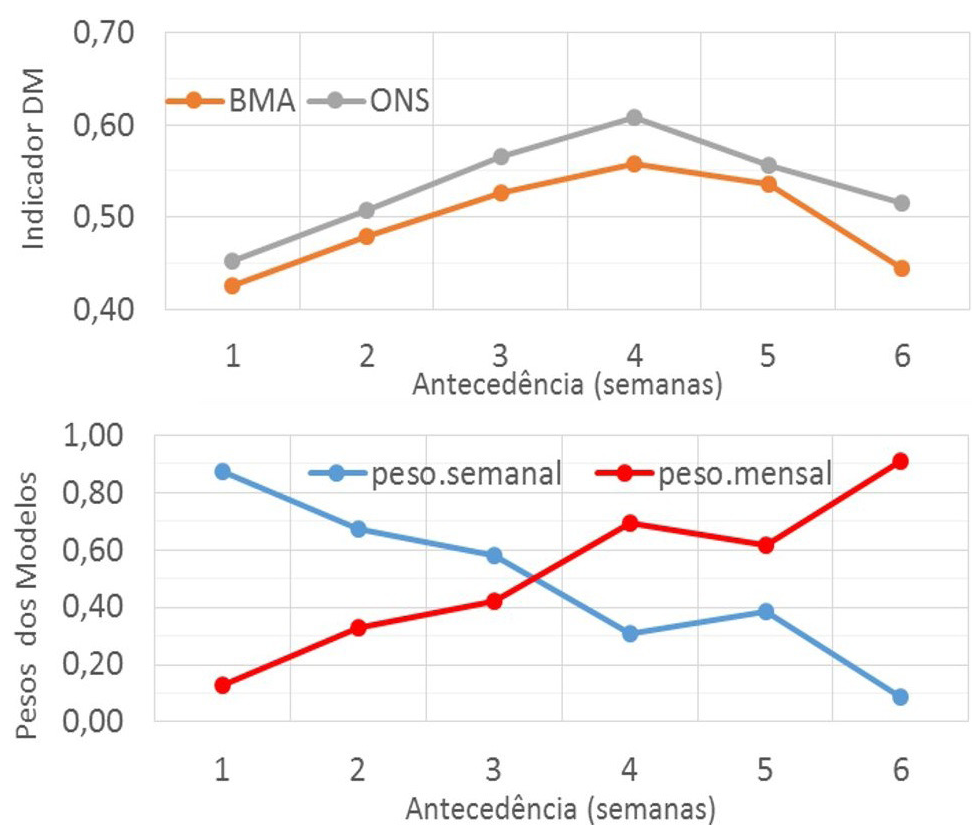

Figura 16. Assim como na Figura 15, mas para a UHE Emborcação. 
Os resultados obtidos para a UHE São Simão (Figura 18), situada no trecho do baixo Paranaíba, mostram uma menor utilização do modelo mensal nas ponderações e o pior desempenho bayesiano em relação às demais usinas da cascata. Assim, quanto mais a montante, maior a utilização do modelo mensal e, portanto, melhores os resultados BMA. Quanto mais a jusante, menor o desempenho do modelo mensal nas usinas da cascata do Paranaíba, reduzindo os pesos mensais e as diferenças entre os indicadores BMA semanais.
Observa-se que as previsões dos modelos semanais adotados pelo ONS para o trecho alto da bacia do Paranaíba, com maior declividade, possuem maiores erros de previsão (maiores índices DM semanais - curvas na cor laranja). Com isso, o modelo mensal é mais exigido nas ponderações, resultando em maiores reduções nos erros semanais (maior descolamento entre as curvas cinza e laranja nos painéis superiores das Figuras 15 a 18). À medida que o rio alcança seus trechos médio e baixo, mais largos, de menor declividade, mais regularizados e com maior área de drenagem
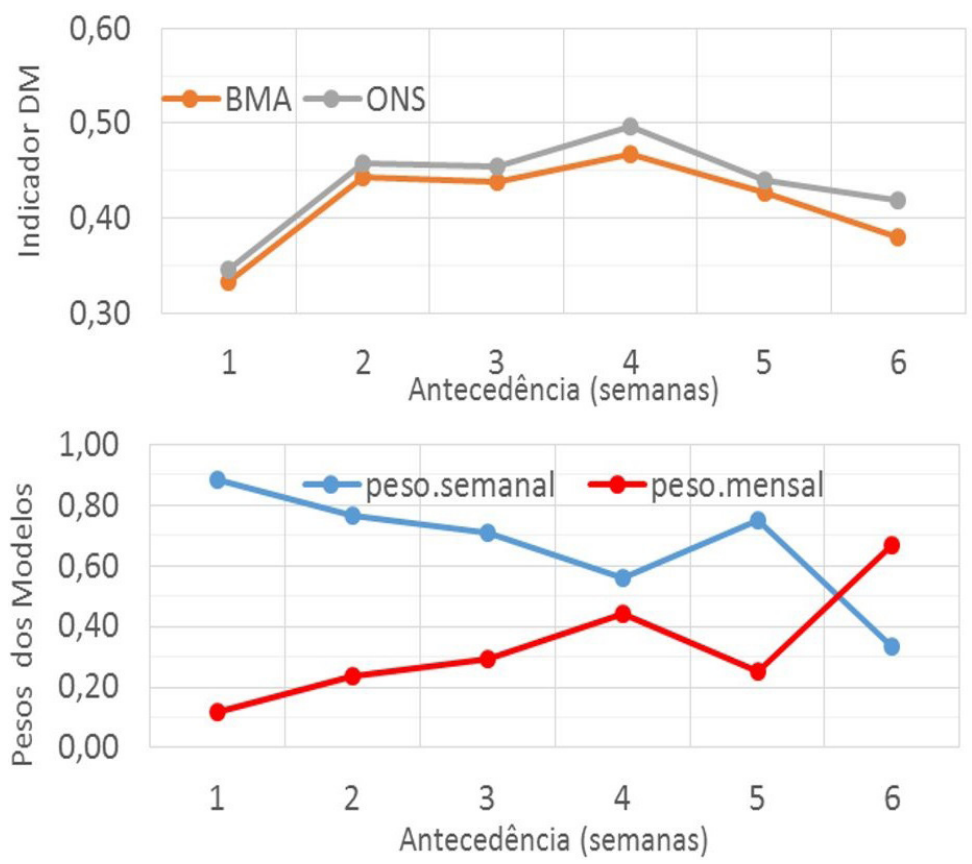

Figura 17. Assim como na Figura 15, mas para a UHE Itumbiara.
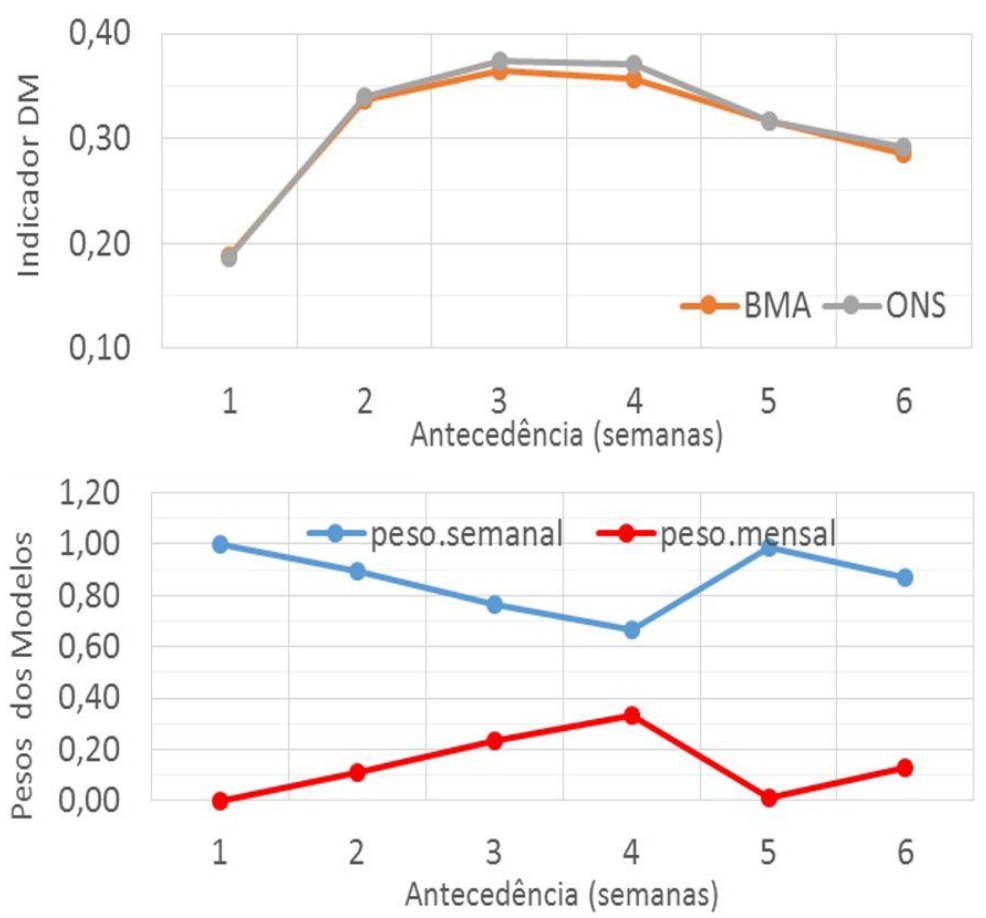

Figura 18. Assim como na Figura 15, mas para a UHE São Simão. 
(mais afluentes como contribuintes), melhoram-se as previsões semanais do ONS (menores DM semanais), reduzindo a utilização dos modelos mensais nas ponderações. Uma discussão detalhada dos resultados obtidos para as demais bacias é apresentada em Oliveira (2015).

A Tabela 3 apresenta um resumo dos resultados desses indicadores para os 28 reservatórios analisados. Observa-se uma relação substancial entre o indicador DM mensal, os erros de previsão dos modelos semanais e a utilização dos pesos mensais nas ponderações. Quando o indicador DM mensal apresenta uma tendência, ao longo do tempo de antecedência, estável ou decrescente (células nas cores amarela e azul, respectivamente, na Tabela 3), a importância do peso semanal nas ponderações acompanha tal tendência.

Dessa forma, a melhoria ou a manutenção no desempenho do modelo mensal durante a transição do lead time semanal das previsões influencia na redução do peso bayesiano semanal. Essa tendência, para o caso das usinas do Paranaíba, foi observada até a quarta semana de antecedência nas previsões. Quando a antecedência semanal atinge a quinta e a sexta semana (células na cor rosa), observa-se o crescimento na utilização dos modelos semanais, mesmo com a melhoria do desempenho do modelo mensal. $\mathrm{O}$ fato de o número de amostras reduzir consideravelmente para os modelos com essas antecedências pode ter contribuído para o menor desempenho das ponderações do que nas outras antecedências.

Ainda em relação à antecedência de cinco e seis semanas, verifica-se na Tabela 3 que 16 usinas situadas nas demais bacias avaliadas apresentam queda de rendimento dos modelos mensais. Essa queda nos resultados das previsões é coincidente com a transição do modelo PARX do lead time mensal igual 1 para o lead time igual a 2, conforme apresentado anteriormente nas Figuras 1 a 7.

Quanto à preponderância dos pesos, doze dos vinte e oito reservatórios mantiveram o modelo semanal como o principal fornecedor nas previsões conjuntas. Nos demais, em três usinas o modelo mensal assumiu o protagonismo na segunda semana de antecedência; dois reservatórios, na terceira semana; cinco, na quarta semana; dois reservatórios, na quinta semana e quatro, na sexta semana de antecedência.

A partir das informações constantes da Tabela 4, entretanto, verifica-se não ser necessário que o modelo mensal assuma o protagonismo das ponderações $\left(w_{2}>0,5\right)$ para que a melhoria nas previsões seja alcançada. A Tabela 4, em seu primeiro bloco, compara a evolução dos pesos dos modelos para as 28 usinas avaliadas em função da antecedência semanal. No segundo bloco, foi avaliado o desempenho do indicador DM semanal.

Tabela 3. Resultados da distribuição dos pesos das ponderações para cada antecedência semanal e da tendência do indicador DM mensal para as 28 usinas avaliadas.

\begin{tabular}{|c|c|c|c|c|c|c|c|c|c|c|}
\hline \multirow{2}{*}{ Reservatório } & \multicolumn{5}{|c|}{ Tendência dos pesos para o modelo Semanal } & \multicolumn{5}{|c|}{ Indicador DM - mensal } \\
\hline & $1-2$ & $2-3$ & $3-4$ & $4-5$ & $5-6$ & $1-2$ & $2-3$ & $3-4$ & $4-5$ & $5-6$ \\
\hline FURNAS & D & $\mathbf{C}$ & D & $\mathbf{C}$ & $\mathbf{D}$ & $\mathbf{D}$ & D & D & C & $\mathbf{D}$ \\
\hline M. MORAES & $\mathbf{D}$ & $\mathrm{C}$ & $\mathbf{D}$ & $\mathbf{C}$ & $\mathbf{E}$ & $\mathbf{D}$ & $\mathbf{D}$ & $\mathbf{D}$ & C & $\mathbf{D}$ \\
\hline MARIMBONDO & $\mathbf{D}$ & $\mathbf{E}$ & $\mathbf{D}$ & $\mathbf{C}$ & $\mathbf{E}$ & D & $\mathrm{D}$ & $\mathrm{D}$ & $\mathrm{C}$ & $\mathbf{E}$ \\
\hline ÁGUA VERMELHA & $\mathbf{D}$ & $\mathbf{E}$ & $\mathbf{D}$ & $\mathrm{C}$ & $\mathbf{D}$ & $\mathbf{D}$ & $\mathbf{D}$ & $\mathrm{D}$ & $\mathrm{C}$ & $\mathrm{C}$ \\
\hline EMBORCAÇÃO & $\mathbf{D}$ & $\mathbf{D}$ & $\mathbf{D}$ & $\mathrm{C}$ & $\mathbf{D}$ & $\mathbf{D}$ & $\mathbf{D}$ & $\mathrm{D}$ & $\mathbf{D}$ & $\mathbf{D}$ \\
\hline NOVA PONTE & $\mathrm{D}$ & D & $\mathrm{D}$ & D & C & $\mathrm{D}$ & D & $\mathrm{D}$ & D & $\mathbf{E}$ \\
\hline ITUMBIARA & D & D & D & $\mathrm{C}$ & $\mathrm{D}$ & $\mathbf{D}$ & D & D & $\mathbf{D}$ & D \\
\hline SÃO SIMÃO & $\mathbf{D}$ & D & $\mathrm{D}$ & $\mathrm{C}$ & $\mathbf{D}$ & $\mathbf{D}$ & $\mathrm{D}$ & $\mathbf{E}$ & $\mathbf{E}$ & $\mathrm{D}$ \\
\hline JURUMIRIM & $\mathbf{D}$ & $\mathbf{E}$ & $\mathbf{D}$ & $\mathbf{D}$ & $\mathrm{C}$ & $\mathbf{E}$ & $\mathbf{E}$ & $\mathrm{E}$ & $\mathrm{C}$ & $\mathrm{C}$ \\
\hline CHAVANTES & $\mathbf{D}$ & $\mathbf{E}$ & $\mathrm{D}$ & $\mathrm{D}$ & $\mathrm{C}$ & $\mathbf{E}$ & $\mathbf{E}$ & $\mathbf{E}$ & $\mathrm{C}$ & $\mathbf{E}$ \\
\hline CAPIVARA & $\mathbf{D}$ & D & $\mathbf{D}$ & $\mathrm{C}$ & $\mathbf{E}$ & $\mathbf{E}$ & $\mathbf{E}$ & $\mathbf{E}$ & $\mathrm{C}$ & $\mathbf{E}$ \\
\hline FOZ DO AREIA & $\mathbf{E}$ & $\mathbf{E}$ & $\mathrm{D}$ & $\mathrm{C}$ & $\mathrm{D}$ & $\mathrm{D}$ & $\mathrm{D}$ & $\mathrm{D}$ & $\mathrm{C}$ & $\mathrm{D}$ \\
\hline SALTO SANTIAGO & $\mathbf{E}$ & $\mathrm{D}$ & $\mathbf{D}$ & $\mathbf{E}$ & $\mathbf{E}$ & $\mathbf{E}$ & $\mathrm{D}$ & $\mathrm{D}$ & $\mathrm{C}$ & $\mathrm{D}$ \\
\hline MACHADINHO & $\mathbf{D}$ & D & $\mathbf{D}$ & $\mathrm{C}$ & $\mathrm{C}$ & $\mathbf{D}$ & $\mathbf{D}$ & $\mathrm{D}$ & $\mathbf{E}$ & $\mathbf{D}$ \\
\hline ITÁ & $\mathbf{D}$ & $\mathbf{D}$ & $\mathbf{D}$ & $\mathrm{C}$ & $\mathrm{C}$ & $\mathbf{D}$ & $\mathrm{D}$ & $\mathrm{D}$ & $\mathbf{E}$ & $\mathrm{D}$ \\
\hline PASSO FUNDO & $\mathbf{D}$ & D & $\mathrm{C}$ & $\mathrm{C}$ & $\mathrm{C}$ & $\mathbf{D}$ & $\mathrm{D}$ & $\mathrm{D}$ & $\mathbf{E}$ & $\mathbf{D}$ \\
\hline PASSO REAL & D & $\mathbf{E}$ & D & $\mathrm{C}$ & $\mathbf{E}$ & D & D & $\mathrm{E}$ & $\mathbf{E}$ & $\mathrm{D}$ \\
\hline BARRA BONITA & $\mathrm{D}$ & $\mathbf{D}$ & $\mathrm{E}$ & $\mathrm{C}$ & $\mathrm{C}$ & $\mathbf{D}$ & $\mathbf{D}$ & $\mathrm{D}$ & $\mathrm{C}$ & $\mathrm{C}$ \\
\hline PROMISSÃO & $\mathbf{D}$ & D & D & $\mathrm{C}$ & $\mathrm{C}$ & D & D & D & $\mathrm{C}$ & C \\
\hline TRÊS IRMÃOS & $\mathrm{D}$ & $\mathbf{E}$ & $\mathbf{D}$ & $\mathrm{C}$ & $\mathrm{C}$ & $\mathbf{D}$ & $\mathbf{D}$ & $\mathrm{D}$ & $\mathrm{C}$ & $\mathbf{D}$ \\
\hline ILHA SOLTEIRA & $\mathbf{D}$ & D & $\mathbf{E}$ & C & $\mathrm{C}$ & D & D & D & $\mathbf{E}$ & $\mathbf{E}$ \\
\hline JUPIÁ & $\mathrm{D}$ & $\mathrm{D}$ & $\mathrm{D}$ & $\mathrm{C}$ & $\mathrm{D}$ & $\mathrm{D}$ & $\mathrm{D}$ & $\mathrm{D}$ & $\mathbf{E}$ & $\mathbf{E}$ \\
\hline ITAIPU & $\mathbf{D}$ & D & $\mathrm{D}$ & $\mathrm{C}$ & $\mathrm{C}$ & $\mathrm{D}$ & $\mathrm{D}$ & D & $\mathrm{C}$ & $\mathrm{D}$ \\
\hline TRÊS MARIAS & $\mathbf{E}$ & $\mathbf{E}$ & $\mathbf{E}$ & $\mathbf{E}$ & $\mathrm{D}$ & $\mathrm{D}$ & $\mathrm{D}$ & $\mathrm{D}$ & $\mathbf{E}$ & $\mathrm{D}$ \\
\hline SOBRADINHO & $\mathbf{D}$ & D & D & $\mathrm{D}$ & D & $\mathbf{E}$ & $\mathbf{E}$ & $\mathbf{E}$ & $\mathrm{C}$ & $\mathbf{E}$ \\
\hline ITAPARICA & $\mathbf{D}$ & D & D & $\mathbf{D}$ & $\mathrm{D}$ & $\mathbf{E}$ & $\mathbf{E}$ & $\mathbf{E}$ & $\mathrm{C}$ & $\mathbf{E}$ \\
\hline SERRA DA MESA & $\mathbf{D}$ & D & $\mathrm{C}$ & $\mathbf{E}$ & $\mathbf{E}$ & $\mathrm{D}$ & $\mathrm{D}$ & $\mathrm{D}$ & $\mathbf{E}$ & $\mathbf{D}$ \\
\hline TUCURUI & $\mathbf{D}$ & $\mathbf{E}$ & $\mathbf{E}$ & $\mathrm{C}$ & $\mathrm{C}$ & $\mathrm{D}$ & $\mathbf{E}$ & $\mathbf{E}$ & $\mathrm{C}$ & $\mathbf{E}$ \\
\hline
\end{tabular}

A letra "D" indica os casos em que a tendência dos pesos é decrescente; a letra " $\mathrm{C}$ " onde a tendência foi crescente e "E", onde a tendência no decorrer das semanas foi estável. 
Tabela 4. Resultados do protagonismo dos pesos e do desempenho do indicador DM semanal para as 28 usinas avaliadas nas previsões entre 1 e 6 semanas de antecedência.

\begin{tabular}{|c|c|c|c|c|c|c|c|c|c|c|c|c|}
\hline \multirow{2}{*}{ Reservatório } & \multicolumn{6}{|c|}{ protagonismo do peso bayesiano } & \multicolumn{6}{|c|}{ Melhor desempenho: indicador DM Semanal } \\
\hline & 1 & 2 & 3 & 4 & 5 & 6 & 1 & 2 & 3 & 4 & 5 & 6 \\
\hline FURNAS & $\mathrm{S}$ & $\mathrm{S}$ & $\mathrm{S}$ & $\mathrm{S}$ & $\mathrm{S}$ & $\mathrm{S}$ & B & B & B & B & $\mathbf{E}$ & B \\
\hline M. MORAES & $\mathrm{S}$ & $\mathrm{S}$ & $\mathrm{S}$ & $\mathrm{S}$ & $\mathrm{S}$ & $\mathrm{S}$ & $\mathbf{B}$ & B & B & B & $\mathbf{E}$ & B \\
\hline MARIMBONDO & $\mathrm{S}$ & $\mathrm{S}$ & $\mathrm{S}$ & $\mathrm{S}$ & $\mathrm{S}$ & $\mathrm{S}$ & $\mathbf{B}$ & B & B & B & B & $\mathbf{B}$ \\
\hline ÁGUA VERMELHA & $\mathrm{S}$ & $\mathrm{S}$ & $\mathrm{S}$ & $\mathrm{S}$ & $\mathrm{S}$ & $\mathrm{S}$ & $\mathrm{B}$ & B & B & B & $\mathbf{B}$ & $\mathrm{B}$ \\
\hline EMBORCAÇÃO & $\mathrm{S}$ & $\mathrm{S}$ & $\mathrm{S}$ & $\mathbf{M}$ & $\mathbf{M}$ & $\mathbf{M}$ & B & B & B & B & $\mathbf{B}$ & B \\
\hline NOVA PONTE & $\mathrm{S}$ & $\mathrm{S}$ & $\mathrm{S}$ & $\mathrm{S}$ & $\mathbf{M}$ & $\mathrm{S}$ & $\mathrm{B}$ & B & B & B & $\mathbf{B}$ & $\mathbf{E}$ \\
\hline ITUMBIARA & $\mathrm{S}$ & $\mathrm{S}$ & $\mathrm{S}$ & $\mathrm{S}$ & $\mathrm{S}$ & $\mathbf{M}$ & $\mathrm{B}$ & $\mathrm{B}$ & B & B & B & B \\
\hline SÃO SIMÃO & $\mathrm{S}$ & $\mathrm{S}$ & $\mathrm{S}$ & $\mathrm{S}$ & $\mathrm{S}$ & $\mathrm{S}$ & $\mathbf{E}$ & $\mathbf{E}$ & $\mathbf{B}$ & $\mathbf{B}$ & $\mathbf{E}$ & $\mathbf{B}$ \\
\hline JURUMIRIM & $\mathrm{S}$ & $\mathbf{M}$ & $\mathrm{S}$ & $\mathbf{M}$ & $\mathbf{M}$ & $\mathrm{E}$ & B & B & B & B & $\mathrm{B}$ & $\mathbf{B}$ \\
\hline CHAVANTES & $\mathrm{S}$ & $\mathrm{S}$ & $\mathrm{S}$ & $\mathbf{M}$ & $\mathbf{M}$ & $\mathrm{S}$ & B & $\mathbf{B}$ & B & B & $\mathbf{B}$ & $\mathbf{B}$ \\
\hline CAPIVARA & $\mathrm{S}$ & $\mathrm{S}$ & $\mathrm{S}$ & $\mathrm{S}$ & $\mathbf{M}$ & $\mathrm{S}$ & B & B & B & $\mathbf{B}$ & B & $\mathbf{B}$ \\
\hline FOZ DO AREIA & $\mathrm{S}$ & $\mathrm{S}$ & $\mathrm{S}$ & $\mathrm{S}$ & $\mathrm{S}$ & $\mathrm{S}$ & $\mathbf{E}$ & $\mathbf{E}$ & $\mathbf{E}$ & B & $\mathbf{E}$ & $\mathbf{B}$ \\
\hline SALTO SANTIAGO & $\mathrm{S}$ & $\mathrm{S}$ & $\mathrm{S}$ & $\mathbf{E}$ & $\mathrm{S}$ & $\mathbf{M}$ & $\mathbf{E}$ & B & B & B & $\mathbf{O}$ & $\mathbf{B}$ \\
\hline MACHADINHO & $\mathrm{S}$ & $\mathrm{S}$ & $\mathrm{S}$ & $\mathbf{M}$ & $\mathbf{M}$ & $\mathbf{M}$ & $\mathbf{O}$ & B & $\mathrm{B}$ & B & $\mathbf{O}$ & $\mathbf{O}$ \\
\hline ITÁ & $\mathrm{S}$ & $\mathrm{S}$ & $\mathrm{S}$ & $\mathbf{M}$ & $\mathbf{M}$ & $\mathbf{M}$ & $\mathbf{O}$ & B & B & B & $\mathrm{O}$ & $\mathbf{O}$ \\
\hline PASSO FUNDO & $\mathrm{S}$ & $\mathbf{M}$ & $\mathbf{M}$ & $\mathrm{S}$ & $\mathrm{S}$ & $\mathrm{S}$ & $\mathbf{E}$ & $\mathbf{O}$ & $\mathbf{E}$ & B & $\mathbf{E}$ & $\mathbf{E}$ \\
\hline PASSO REAL & $\mathrm{S}$ & $\mathbf{M}$ & $\mathbf{M}$ & $\mathbf{M}$ & $\mathrm{S}$ & $\mathrm{S}$ & $\mathrm{B}$ & $\mathrm{B}$ & $\mathrm{B}$ & B & $\mathrm{B}$ & $\mathrm{B}$ \\
\hline BARRA BONITA & $\mathrm{S}$ & $\mathrm{S}$ & $\mathbf{M}$ & $\mathbf{M}$ & $\mathrm{S}$ & $\mathrm{S}$ & $\mathbf{B}$ & $\mathbf{B}$ & B & B & $\mathbf{O}$ & $\mathbf{O}$ \\
\hline PROMISSÃO & $\mathrm{S}$ & $\mathrm{S}$ & $\mathbf{M}$ & $\mathbf{M}$ & $\mathrm{S}$ & $\mathrm{S}$ & B & B & B & B & B & $\mathbf{E}$ \\
\hline TRÊS IRMÃOS & $\mathrm{S}$ & $\mathrm{S}$ & $\mathrm{S}$ & $\mathbf{M}$ & $\mathbf{M}$ & $\mathrm{S}$ & $\mathrm{B}$ & $\mathbf{B}$ & $\mathbf{B}$ & B & $\mathbf{B}$ & B \\
\hline ILHA SOLTEIRA & $\mathrm{S}$ & $\mathrm{S}$ & $\mathrm{S}$ & $\mathrm{S}$ & $\mathrm{S}$ & $\mathrm{S}$ & $\mathbf{E}$ & B & B & B & $\mathbf{B}$ & B \\
\hline JUPIÁ & $\mathrm{S}$ & $\mathrm{S}$ & $\mathrm{S}$ & $\mathrm{S}$ & $\mathrm{S}$ & $\mathrm{S}$ & $\mathbf{E}$ & $\mathrm{E}$ & B & B & $\mathbf{B}$ & B \\
\hline ITAIPU & $\mathrm{S}$ & $\mathrm{S}$ & $\mathrm{S}$ & $\mathrm{S}$ & $\mathrm{S}$ & $\mathrm{S}$ & $\mathbf{E}$ & B & B & B & $\mathbf{B}$ & $\mathbf{E}$ \\
\hline TRÊS MARIAS & $\mathrm{S}$ & $\mathrm{S}$ & $\mathrm{S}$ & $\mathrm{S}$ & $\mathrm{S}$ & $\mathrm{S}$ & $\mathrm{O}$ & $\mathbf{E}$ & $\mathbf{E}$ & $\mathbf{E}$ & $\mathbf{O}$ & B \\
\hline SOBRADINHO & $\mathrm{S}$ & $\mathrm{S}$ & $\mathrm{S}$ & $\mathrm{S}$ & $\mathrm{S}$ & $\mathbf{M}$ & $\mathbf{E}$ & $\mathbf{E}$ & $\mathbf{E}$ & $\mathbf{E}$ & B & B \\
\hline ITAPARICA & $\mathrm{S}$ & $\mathrm{S}$ & $\mathrm{S}$ & $\mathrm{S}$ & $\mathrm{S}$ & $\mathbf{M}$ & $\mathbf{E}$ & $\mathbf{E}$ & $\mathbf{E}$ & $\mathbf{E}$ & $\mathbf{B}$ & $\mathbf{B}$ \\
\hline SERRA DA MESA & $\mathrm{S}$ & $\mathrm{S}$ & $\mathrm{S}$ & $\mathrm{S}$ & $\mathrm{S}$ & $\mathrm{S}$ & B & B & B & B & B & $\mathbf{E}$ \\
\hline TUCURUI & $\mathrm{S}$ & $\mathrm{S}$ & $\mathrm{S}$ & $\mathrm{S}$ & $\mathrm{S}$ & $\mathrm{S}$ & $\mathbf{E}$ & $\mathrm{O}$ & $\mathrm{O}$ & $\mathrm{B}$ & $\mathrm{E}$ & $\mathbf{E}$ \\
\hline
\end{tabular}

Para as colunas da tabela que avaliaram os pesos dos modelos, a letra "S" indica que o modelo semanal foi preponderante nas ponderações e a letra "M", nos casos em que o modelo mensal foi protagonista. Na avaliação do desempenho do indicador, a letra "B" indica os casos em que o modelo BMA superou os modelos utilizados pelo ONS; a letra "O” indica as ocorrências contrárias; e a letra "E” aponta para os casos de equilíbrio entre as avaliações.

Especificamente para os resultados nos quatro aproveitamentos do Paranaíba, de um total de 24 casos (4 usinas versus 6 semanas), em apenas cinco deles (células na cor cinza claro) o peso mensal superou o semanal. Quando considerado o escopo de todos os reservatórios, o peso mensal ultrapassou o semanal em apenas 31 das 168 possibilidades.

Haja vista a grande quantidade de previsões BMA que se mostram melhores ou similares do que os resultados das previsões semanais realizadas pelo ONS, pode-se inferir que pequenas parcelas de contribuição dos modelos mensais nas ponderações, desde que atestado o bom desempenho desses modelos em validações cruzadas, são capazes de propiciar melhorias significativas aos modelos semanais. De fato, de um total de 168 previsões (28 reservatórios versus 6 semanas de antecedência), as previsões semanais com o uso da técnica BMA proposta superam em 118 casos (células B de cor laranja na Tabela 4) as previsões semanais realizadas pelo ONS, que foi superior apenas em 14 casos (células $\mathbf{O}$ de cor verde na Tabela 4). Em 36 ocasiões (células $\mathbf{E}$ de cor amarela na Tabela 4) não foi possível identificar diferenças estatisticamente significantes entre as previsões realizadas pelo ONS e as previsões obtidas via modelo BMA proposto.

\section{CONCLUSÃO}

Formulou-se neste artigo uma proposta para o aperfeiçoamento das previsões de afluências semanais aos reservatórios do sistema hidroelétrico brasileiro por meio de metodologia de integração de previsões na escala mensal com as previsões na escala semanal. Tradicionalmente, essas previsões não estão conectadas, embora os modelos de otimização que fazem uso das mesmas estejam todos integrados.

As previsões mensais foram realizadas por meio de um modelo periódico auto-regressivo exógeno (PARX) com uso de informações climáticas, que apresentaram melhor desempenho nessa escala temporal quando comparado a modelos auto-regressivos. As previsões mensais foram acopladas às previsões semanais dos modelos utilizados pelo ONS a partir da técnica de ponderação bayesiana de modelos (BMA).

Os resultados apontam para o êxito da aplicação da metodologia BMA a julgar pela melhoria dos indicadores de qualidade adotados. O acoplamento bayesiano das previsões mensais de vazão começa a fornecer informação útil para as previsões semanais mesmo a partir das previsões com uma semana 
de antecedência, tornando-se inclusive o modelo preferencial para previsões de alguns dos reservatórios a partir da segunda semana de antecedência.

A avaliação das distribuições dos pesos dos modelos de acordo com a antecedência da previsão apresentou um gradativo crescimento na importância do modelo mensal, que atingiu o protagonismo dos modelos em lead times semanais distintos para dezesseis dos vinte e oito reservatórios.

Quanto ao critério de distribuição dos pesos dos modelos, verificou-se haver significativa relação entre a evolução do indicador DM mensal no decorrer das antecedências de previsão e a utilização dos modelos mensais nas ponderações. Assim, se o indicador DM, no decorrer das antecedências semanais, possuir tendência de melhoria ou de estabilização, o peso do modelo mensal será maior nas ponderações.

Observou-se ainda que a evolução dos pesos dos modelos em função da antecedência das previsões varia não somente entre as bacias, mas também dentro de uma mesma bacia, como o caso do rio Paranaíba, em que as previsões para o trecho alto do rio, com maior declividade, utilizaram-se mais do modelo mensal nas ponderações. À medida que o rio flui para seus trechos médio e baixo que são mais regularizados, reduz-se a utilização dos modelos mensais. Quanto maior a utilização dos pesos mensais, maior serão as melhorias nas previsões semanais agregadas.

Haja vista a grande quantidade de previsões BMA que se mostraram melhores ou similares aos resultados das previsões semanais realizadas pelo ONS, verifica-se não ser necessário que o modelo mensal assuma o protagonismo das ponderações $\left(w_{2}>0,5\right)$ para que melhores previsões sejam alcançadas. Pequenas parcelas de contribuição dos modelos mensais nas ponderações, desde que atestado o bom desempenho dos modelos mensais, são capazes de propiciar melhorias aos modelos semanais.

A variabilidade observada nos pesos dos modelos mensal e semanal decorre da qualidade das previsões desses modelos obtida via validação cruzada para o período de janeiro de 2009 a setembro de 2014. O desempenho individual de cada modelo variou conforme o reservatório e período analisado, sendo decorrente das características hidrogeomorfológicas da bacia de drenagem e dos padrões climáticos de larga escala associados com a variabilidade da chuva e vazão na referida bacia. Uma discussão mais detalhada aparece em Oliveira (2015), porém mais estudos são necessários para entender a dinâmica espaço-temporal das relações entre desempenho dos modelos e características hidrogeomorfológicas e climáticas das bacias em estudo.

Finalmente, a praticidade de implementação da técnica BMA nas atuais previsões desempenhadas pelo ONS, aliada ao ganho significativo do modelo combinado nas previsões, motiva a realização de outros estudos. Trabalhos futuros poderão incluir o acoplamento dos resultados obtidos nas usinas de montante para as ponderações bayesianas da usina de jusante, buscando ampliar a correlação espacial entre elas. Poderão ainda ser adotados outros indicadores climáticos, como por exemplo os relacionados aos eventos El Niño Modoki ou mesmo indicadores de base trimestral. O ganho obtido nas previsões semanais a partir do modelo BMA poderá ainda ser quantificado em termos energéticos e de custos a partir do uso dessas previsões em modelos energéticos.

\section{AGRADECIMENTOS}

Os autores agradecem ao ONS, por disponibilizar as informações referentes às previsões semanais de vazão constantes dos relatórios do PMO e aos revisores, pelas relevantes contribuições à elaboração da versão final do artigo.

\section{REFERÊNCIAS}

ANEEL - AGÊNCIA NACIONAL DE ENERGIA ELÉTRICA. Banco de informações de geração. Brasília, 2016. Disponível em: < http:/ / www.aneel.gov.br>. Acesso em: 4 maio 2016.

BARROS, M. T. L.; TSAI, F. T.-C.; YANG, S.-L.; LOPES, J. E. G.; YEH, W. W.-G. Optmization of Large-Scale Hydropower System Operations. Journal of Water Resources Planning and Management, v. 129, n. 3, p. 178-188, 2003. http://dx.doi.org/10.1061/(ASCE)07339496(2003)129:3(178).

CARDOSO, A. O.; DIAS, P. L. S. The relationship between ENSO and Paraná River Flow. Advances in Geosciences, v. 6, p. 189-193, 2006. http:/ /dx.doi.org/10.5194/adgeo-6-189-2006.

CASTANHARO, G.; GIBERTONI, R. F. C.; MÜLLER, I. I.; ANDRIOLO, M. V.; KAVISKI, E.; GUILHON, L. G. F.; ROCHA, V. F. Previsão de vazões na Bacia do Rio Iguaçu baseada no modelo SMAP e com incorporação de informações de precipitação. Revista Brasileira de Recursos Hídricos, v. 12, n. 3, p. 57-68, 2007. http:// dx.doi.org/10.21168/rbrh.v12n3.p57-68.

CATALDI, M.; MACHADO, C. O.; GUILHON, L. G. F.; CHOU, S. C.; GOMES, J. L.; BUSTAMANTE, J. F. Análise das previsões de precipitação obtidas com a utilização do modelo Eta como insumo para modelos de previsão semanal de vazão natural. Revista Brasileira de Recursos Hídricos, v. 12, n. 3, p. 5-12, 2007. http://dx.doi. org/10.21168/rbrh.v12n3.p5-12.

CEPEL - CENTRO DE PESQUISAS DE ENERGIA ELÉTRICA. Manual de referência do modelo GEVAZP: modelo de geração de séries sintéticas de energias e vazões periódicas. Rio de Janeiro, 2002a.

CEPEL - CENTRO DE PESQUISAS DE ENERGIA ELÉTRICA. Manual de referencia do modelo PREVIVAZH: modelos computacionais para previsão de afluências diárias, semanais e mensais. Versão 2.5. Rio de Janeiro, 2002b.

CEPEL - CENTRO DE PESQUISAS DE ENERGIA ELÉTRICA. Manual de referência do modelo DESSEM: modelo de despacho hidrotérmico de curto prazo. Versão 8.2a. Rio de Janeiro, 2003.

CEPEL - CENTRO DE PESQUISAS DE ENERGIA ELÉTRICA. Manual de referência do modelo PREVIVAZ: modelo de previsão de vazões semanais aplicado ao sistema hidroelétrico brasileiro. Rio de Janeiro, 2004.

CEPEL - CENTRO DE PESQUISAS DE ENERGIA ELÉTRICA. Manual de referência do modelo NEWAVE: modelo de planejamento 
da operação de sistemas hidrotérmicos interligados de longo e médio prazo. Rio de Janeiro, 2006.

CEPEL - CENTRO DE PESQUISAS DE ENERGIA ELÉTRICA. Manual de referência do modelo DECOMP: modelo de determinação da coordenação da operação. Versão 18.3. Rio de Janeiro, 2013.

COELHO, C. A. S.; UVO, C. B.; AMBRIZZI, T. Exploring the impacts of the tropical pacific SST on the precipitation patterns over South America during ENSO periods. Theoretical and Applied Climatology, v. 71, n. 3-4, p. 185-197, 2002. http://dx.doi. org/10.1007/s007040200004.

COLLISCHONN, W.; TUCCI, C. E. M.; CLARKE, R. T.; CORBO, M. D.; SILVA, B. C.; COLLISCHONN, B.; ALLASIA, D.; PAZ, A. R. Modelo hidrológico distribuído para previsão de vazões incrementais na bacia do Rio Paranaíba entre Itumbiara e São Simão. Revista Brasileira de Recursos Hídricos, v. 12, n. 3, p. 43-55, 2007.

COSTA, F. S.; MACEIRA, M. E. P.; DAMÁZIO, J. M. Modelos de previsão hidrológica aplicados ao planejamento da operação do sistema elétrico brasileiro. Revista Brasileira de Recursos Hídricos, v. 12, n. 3, p. 21-30, 2007.

DEMPSTER, A.; LAIRD, N.; RUBIN, D. Maximum likelihood from incomplete data via the EM algorithm (with discussion). Journal of the Royal Statistical Society. Series A (General), v. 39, p. 1-38, 1977.

DIAZ, H. F.; MARKGRAF, V. El Niño and the southern oscillation: multiscale variability and global and regional impacts. Cambridge: Cambridge University Press, 2000. p. 259-270. http://dx.doi. org/10.1017/CBO9780511573125.

DIEBOLD, F. X.; MARIANO, R. Comparing predictive accuracy. Journal of Business \& Economic Statistics, v. 13, p. 253-265, 1995.

FADIGA JUNIOR, F. M.; LOPES, J. E. G.; MARTINS, J. R. S.; BARROS, M. T. L.; SANTOS, R. C. P. Modelos de previsão de vazões para a bacia incremental à UHE Itaipu. Revista Brasileira de Recursos Hídricos, v. 13, n. 2, p. 65-75, 2008. http://dx.doi. org/10.21168/rbrh.v13n2.p65-75.

FRALEY, C.; RAFTERY, A. E.; GNEITING, T. Calibrating multimodel forecast ensembles with exchangeable and missing members using bayesian model averaging. Monthly Weather Review, v. 138, n. 1, p. 190-202, 2010. http://dx.doi.org/10.1175/2009MWR3046.1.

GIBBONS, J. M.; COX, G. M.; WOOD, A. T. A.; CRAIGON, J.; RAMSDEN, S. J.; TARSITANO, D.; CROUT, N. M. J. Applying Bayesian Model Averaging to mechanistic models: An example and comparison of methods. Environmental Modelling \& Software, v. 23, n. 8, p. 973-985, 2008. http://dx.doi.org/10.1016/j. envsoft.2007.11.008.

GOMIDE, F. L. S. Hydropower development in Brazil: experiences and perspectives. In: UNITED NATIONS SYMPOSIUM ON HYDROPOWER AND SUSTAINABLE DEVELOPMENT,
2004, Beijing, China. Proceedings... China: National Development and Reform Commission, 2004.

GRIMM, A. M. How do La Niña events disturb the summer monsoon system in Brazil? Climate Dynamics, v. 22, n. 2-3, p. 123 138, 2004. http://dx.doi.org/10.1007/s00382-003-0368-7.

GRIMM, A. M.; BARROS, V. R.; DOYLE, M. E. Climate variability in southern South America associated with El Niño and La Niña events. Journal of Climate, v. 13, n. 1, p. 35-58, 2000. http://dx.doi. org/10.1175/1520-0442(2000)013<0035:CVISSA>2.0.CO;2.

HASTIE, T. J.; TIBSHIRANI, R. J.; FRIEDMAN, J. The elements of statistical learning: data mining, inference, and prediction. 2. ed. New York: Springer-Verlag, 2009.. http://dx.doi.org/10.1007/9780-387-84858-7.

HOETING, J. A.; MADIGAN, D.; RAFTERY, A. E.; VOLINSKY, C. T. Bayesian model averaging: a tutorial. Statistical Science, v. 14, p. 382-417, 1999.

IRI - INTERNATIONAL RESEARCH INSTITUTE FOR CLIMATE AND SOCIETY. Kaplan Extended v2 ssta: SST anomaly data. Palisades, 2016a. Disponível em: <http://iridl.ldeo.columbia. edu/SOURCES/.KAPLAN/.EXTENDED/.v2/.ssta/>. Acesso em: 7 mar. 2016.

IRI - INTERNATIONAL RESEARCH INSTITUTE FOR CLIMATE AND SOCIETY. NOAA NCEP-NCAR CDAS-1 MONTHLY Intrinsic PressureLevel u: zonal wind data. Palisades, 2016b. Disponível em: < http://iridl.ldeo.columbia.edu/SOURCES/. NOAA/.NCEP-NCAR/.CDAS-1/.MONTHLY/.Intrinsic/. PressureLevel/.u/>. Acesso em: 7 mar. 2016.

KAPLAN, A.; CANE, M.; KUSHNIR, Y.; CLEMENT, A.; BLUMENTHAL, M.; RAJAGOPALAN, B. Analyses of global sea surface temperature 1856-1991. Journal of Geophysical Research, v. 103, n. C9, p. 18567-18589, 1998. http://dx.doi.org/10.1029/97JC01736.

LIMA, C. H. R. Connecting multiscale streamflow forecasts for the hydropower system in Brazil Using Bayesian Model Averaging and Markov Chain Monte Carlo Sampling, In: ITISE 2014: INTERNATIONAL WORK-CONFERENCE ON TIME SERIES, 2014, Granada. Proceedings... Granada: Copicentro Granada S.L., 2014. v. 2.

LIMA, C. H. R.; LALL, U. Climate informed long term seasonal forecasts of hydroenergy inflow for the Brazilian hydropower system. Journal of Hydrology, v. 381, n. 1-2, p. 65-75, 2010a. http:// dx.doi.org/10.1016/j.jhydrol.2009.11.026.

LIMA, C. H. R.; LALL, U. Climate informed monthly streamflow forecasts for the Brazilian hydropower network using a periodic ridge regression model. Journal of Hydrology, v. 380, n. 3-4, p. 438449, 2010b. http://dx.doi.org/10.1016/j.jhydrol.2009.11.016. 
LINK, W. A.; BARKER, R. J. Model weights and the foundations of multimodel inference. Ecology, v. 87, n. 10, p. 2626-2635, 2006. http://dx.doi.org/10.1890/0012-9658(2006)87[2626:MWATFO ]2.0.CO;2. PMid:17089670.

MACEIRA, M. E. P.; PENNA, D. D. J.; DAMÁZIO, J. M. Geração de cenários sintéticos de energia e vazão para o planejamento da operação energética. Cadernos do IME: Série Estatística, v. 21, p. 11-35, 2006.

OLIVEIRA, V. G. Atualização das previsões de curto pražo de afluências ao sistema hidroelétrico brasileiro a partir da técnica de ponderação bayesiana e de previsões mensais de afluência com uso de informação climática. 2015. 150 f. Dissertação (Mestrado em Tecnologia Ambiental e Recursos Hídricos) - Departamento de Engenharia Civil e Ambiental, Universidade de Brasília, Brasília, 2015. Disponível em: <http:/ / www.ptarh.unb.br/downloads/dissertacoes/169-2015.pdf $>$. Acesso em: 11 maio 2016.

ONS - OPERADOR NACIONAL DO SISTEMA ELÉTRICO. Relatório anual de avaliação das previsões de vazões: 2014. Brasília, 2015. Disponível em: < http://www.ons.org.br/operacao/previsao_vazoes. aspx $>$. Acesso em: 2 maio 2016.

REYNOLDS, R. W.; SMITH, T. M. Improved global sea surface temperature analyses using optimum interpolation. Journal of Climate, v. 7, n. 6, p. 929-948, 1994. http://dx.doi.org/10.1175/15200442(1994)007<0929:IGSSTA>2.0.CO;2.
SILVA, B. C.; COLLISCHONN, W.; TUCCI, C. E. M.; CLARKE, R. T.; DELGADO, M. C. Previsão hidroclimática de vazão de curto prazo na bacia do rio São Francisco. Revista Brasileira de Recursos Hidricos, v. 12, n. 3, p. 31-42, 2007. http://dx.doi.org/10.21168/ rbrh.v12n3.p31-41.

SILVA, B. C.; TUCCI, C. E. M.; COLLISCHONN, W. Previsão de vazão com modelos hidroclimáticos. Revista Brasileira de Recursos Hidricos, v. 11, n. 3, p. 15-30, 2006. http://dx.doi.org/10.21168/ rbrh.v11n3.p15-29.

VRUGT, J. A.; DIKS, C. G. H.; CLARK, M. P. Ensemble Bayesian model averaging using Markov Chain Monte Carlo sampling. Environmental Fluid Mechanics, v. 8, n. 5-6, p. 579-595, 2008. http:// dx.doi.org/10.1007/s10652-008-9106-3.

\section{Contribuição dos autores}

Vinicius Grossi de Oliveira: coleta dos dados primários e secundários, mineração dos dados, elaboração do código computacional, aplicação dos modelos, interpretação dos resultados, elaboração e revisão do texto.

Carlos Henrique Ribeiro Lima: concepção do trabalho, desenvolvimento dos algoritmos, elaboração do código computacional, interpretação dos resultados, organização, elaboração e revisão do texto. 